\title{
CD200:CD200R-Mediated Regulation of Immunity
}

\author{
Reginald M. Gorczynski \\ Departments of Surgery and Immunology, University Health Network and The Toronto Hospital, Toronto, ON, Canada M5G1L7
}

Correspondence should be addressed to Reginald M. Gorczynski, rgorczynski@uhnres.utoronto.ca

Received 22 October 2012; Accepted 14 November 2012

Academic Editors: R. Orentas and P. Puccetti

Copyright ( 2012 Reginald M. Gorczynski. This is an open access article distributed under the Creative Commons Attribution License, which permits unrestricted use, distribution, and reproduction in any medium, provided the original work is properly cited.

\begin{abstract}
The type 1 membrane glycoprotein CD200, widely expressed on multiple cells/tissues, uses a structurally similar receptor (CD200R1), whose expression is more restricted to cells of the myeloid and lymphoid lineages, to transmit signals affecting responses in multiple physiological systems. Thus CD200 expression is reported to exert effects on cancer growth, autoimmune and allergic disorders, infection, transplantation, bone development and homeostasis, and reproductive biology. It was initially thought, based on the idea that CD200R1 was mostly expressed on cells of myeloid origin, that CD200:CD200R1 interactions were primarily dedicated to controlling myeloid cell function. However additional members of the CD200R family have now also been identified, although their function(s) remain unclear, and CD200R1 itself is now known to be expressed by subsets of T cells and other cells. Together these observations add layers of complexity to our understanding of CD200-related regulation. In common with a number of physiological systems, the mechanism(s) of CD200-induced signaling seem to fit within a similar framework of opposing actions of kinases and phosphatases. This paper highlights the advances in our knowledge of immunoregulation achieved following CD200:CD200R interaction and the potential clinical applicability of that information.
\end{abstract}

\section{Introduction}

\subsection{Structure: Function Analysis of CD200:CD200R}

1.1.1. The Structures of CD200 and CD200R. Rat CD200 (initially referred to as OX2) was characterized as a 41 - to 47-kDa cell-surface glycoprotein in 1982 [1] and reported to be expressed on multiple cell types, including thymocytes, B cells, activated $\mathrm{T}$ cells, follicular dendritic cells, skin and cells in the central nervous system (CNS), and reproductive organs [2-5]. Sequence analysis showed it belonged to the immunoglobulin superfamily (IgSF), with two IgSF domains, a single transmembrane domain, and a short cytoplasmic domain [1]. Subsequent studies showed that its distribution was relatively conserved across species consistent with the molecule having an important biological function. The lack of signaling motifs in either of the two latter domains implied it might signal following binding to a cell-surface receptor (CD200R).

Gene cloning was used independently by two groups to identify a molecule (CD200R1) recognized by an antibody which blocked CD200 binding to macrophages. CD200R1 also bound a soluble chimeric protein in which the extracellular domains of CD200 were linked with the mouse immunoglobulin Fc region [6, 7]. Like CD200, CD200R1 contains two IgSF domains, but the longer cytoplasmic domain has a potential signaling capacity. Using a variety of molecular techniques, other members of the CD200R family were identified and referred to as CD200R(2-5) or CD200RLa-d (for CD200R-like) [6, 7]. Only CD200R1 expressed the long cytoplasmic tail, with alternate CD200Rs containing a short cytoplasmic region and a positively charged lysine residue in the transmembrane region, which it was hypothesized would form a salt bridge with adapter molecules (e.g., DAP12) to enable signal transduction (albeit via a different pathway than CD200R1). It was felt that the alternate CD200Rs might use a different ligand (to CD200) and thus exert a different function to CD200R1 [8].

Myeloid lineage-derived mononuclear cells play a key role in the regulation of the immune system which enables a response to foreign antigen or infectious organisms to take place without simultaneously compromising reactivity to self 
[9]. Reestablishment of immunological homeostasis following activation to respond to infectious insult involves termination of survival of activated lymphocytes and induction of a programmed cell death (apoptotic) response. In addition, the biological functions of proinflammatory macrophages are redirected to alternate functions including humoral immunity and wound healing [10]. Although regulation is predominantly under control of cytokines [11], regulation by myeloid cells is important in "fine tuning" $[12,13]$, and altered integration of the composite of activating/inhibitory signaling through such receptors is thought to contribute to many autoimmune processes [14-16].

The expression of CD200R1 on cells of the myeloid lineage [17], along with data concerning the relatively ubiquitous distribution of CD200, suggested similarities between CD200:CD200R and CD47-CD172a (SIRP- $\alpha$ ). CD172a signaling downregulates myeloid cells through the tyrosine phosphatases SHP1 and SHP2 [18]. CD200 was also structurally likened to the costimulatory molecules CD80 and CD86, which in turn are ligands for the activating receptor CD28 and inhibitory receptor CD152 expressed by T cells, and it was suggested that CD200 might thus function as an alternate immune activating molecule [19], although in these studies the function observed seemed independent of CD200R1. More detailed investigations concluded that expression of CD200 was correlated with suppression of immunity in an allotransplant model [20], and graft rejection occurred following neutralization of expression of CD200 [21]. Detailed characterization of immunoregulation by CD200:CD200R has come from studies with CD200 transgenic $\left(\mathrm{CD} 200^{\mathrm{tg}}\right)$ and CD200 (or CD200R) deficient mice (CD200KO; CD200R1KO), see the following.

1.1.2. Physical Interaction between CD200:CD200R. Information concerning the physical interactions between CD200 and CD200R has come essentially from two methodologies. One has focused on studying the structural constraints and biophysical properties of the interacting molecules. Using site-directed mutagenesis of CD200R1 Hatherley and Barclay showed that, like CD200, this molecule interacts predominantly with CD200 through the GFCC' face of its N-terminal domain, suggesting in turn that the cell-cell interaction

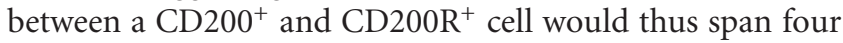
Ig superfamily domains, a distance similar to many of the interactions found between $\mathrm{T}$ cells and antigen presenting cells [22]. The actual affinity of interaction between CD200 and CD200R is reportedly quite low $(\mathrm{KD} \sim 2.5 \mu \mathrm{M})$ [23], similar to that of many other interactions in the immune system which may imply that these serve to modulate cell activity in the context of other cell:cell interactions.

Similar conclusions concerning the importance of interaction between the N-terminal domains of CD200/CD200R were reached from functional studies which focused on the ability of CD200 and CD200R-derived peptides to act as agonists or antagonists of the immune responses set in train by CD200:CD200R interactions [24, 25]. As an example, since CD200 was shown to attenuate inflammatory cytokine production following stimulation of lymphocytes by LPS in vitro, or TNF $\alpha$ production in vivo after LPS injection, CD200 peptides which antagonized this activity, or alternatively acted independently as agonists, were characterized [24]. Regions in the N-terminal FR2 $\rightarrow$ CDR2 and CDR2 $\rightarrow$ FR3 domains of CD200 were most relevant for the functional effects seen [24].

\subsubsection{Biochemical Events following CD200:CD200R Interac-} tions. The paired inhibitory/activating receptors on myeloid cells fall into two categories, namely, those belonging to the immunoglobulin superfamily and those belonging to the C-type lectin family, both of which are also expressed on natural killer (NK) cells as well as myeloid cells [26]. Members of the immunoglobulin superfamily include the paired immunoglobulin-like receptors (PIRs) [27]; immunoglobulin-like receptors (ILTs) in humans [28]; the so-called signal regulatory proteins (SIRPS) [29]; and the triggering receptors expressed by myeloid cells (TREMs), of which the CD200Rs represent members [16]. Investigations into the biochemistry of signaling through CD200Rs have focused on the cytoplasmic region of the receptor. CD200R1 contains an NPXY motif able to interact with PTB binding domains found in several signaling adaptor molecules, a feature evident in human as well as murine CD200R1 [6]. Despite the evidence which suggested that CD200R1 fits within the category of myeloid "inhibitor receptors," such as Fc $\gamma$ RIIB, the molecule was not found to possess a classical ITIM motif [12] which, after tyrosine phosphorylation (e.g., by Src [30]), would in turn recruit phosphatases (SHP/SHIP1) to suppress cell activation by promoting dephosphorylation. Instead tyrosine phosphorylation occurring following CD200:CD200R1 interactions depends upon the NPXY motif, leading to phosphorylation of Dok1 and Dok2 proteins, binding of RasGAP and SHIP, and subsequent downstream inhibition of the RasMAPK pathways [31]. Further light on this process has come from more recent studies by Mihrshahi and Brown [32]. This group reported that CD200R1-induced phosphorylation of Dok2 preceded phosphorylation of Dok1, with recruitment of different downstream proteins by Dok2 and Dok1. Dok1 recruited considerably less RasGAP than Dok2, which also recruited the adaptor molecule Nck following CD200:CD200R1 interaction, while in contrast phosphorylation of Dok1 led to recruitment of CrkL. Using "knockdown" of Dok1 and CrkL expression in U937 cells, they showed increased Dok2 phosphorylation and RasGAP recruitment to Dok2, which the authors concluded best supported a model in which Dok1 negatively regulates Dok2mediated CD200R1 signaling through recruitment of CrkL.

Few studies have focused on the functional significance of CD200Rs besides CD200R1, the prototype of inhibitory CD200Rs, or indeed on the biochemical pathways triggered by them [33]. Unlike CD200R1, alternate CD200Rs lack cytoplasmic domains able to recruit signaling molecules directly and are thought to function by coopting accessory molecules (e.g., DAP12) for their function [34]. A role for alternate CD200Rs has been reported in regulation of differentiation of "tolerogenic" DCs, able to foster development of Foxp $3^{+}$Tregs [35]. Voehringer et al. have also suggested a role for an alternate CD200R, expressed in basophils and 
mast cells, in recruitment of DAP12 to the cell surface. However, this group was unable to establish a connection between recruitment of DAP12 and effector cell recruitment or the host response elicited by helminth infection with Nippostrongylus brasiliensis [36].

We have recently reviewed extensively the structure/function properties of alternate CD200Rs in mouse models [37]. Since CD200Rs show extensive homology in their extracellular region, generating anti-CD200R-specific antibodies is acknowledged to be a challenge. We generated $\mathrm{mAbs}$ specific for murine (m)CD200R1/R2 and showed that $\mathrm{mR} 2$ was expressed on the cell surface in the absence of the adaptor protein Dap12. Despite homology between $\mathrm{mR} 1$ and $\mathrm{mR} 4$, the unexpected reduction in the molecular mass (i.e., $90 \mathrm{kDa}$ versus $48 \mathrm{kDa}$ ) between the two receptors implied that the transmembrane and cytoplasmic region of mR4 regulated glycosylation. Substitution of the transmembrane and cytoplasmic region of $\mathrm{mR} 1$ and $\mathrm{mR} 2$ with that of mR4 (to produce mR1r4 and mR2r4, resp.) was found to reduce glycosylation of the chimeric receptors $\mathrm{mR} 1 \mathrm{r} 4$ and $\mathrm{mR} 2 \mathrm{r} 4$, implying that these regions regulated the glycosylation of mCD200Rs. In activation experiments, phosphorylation of Dap12 following interaction with CD200 occurred on cells expressing mR2V5 but not mR4V5. Similar experiments with the chimeric receptors $\mathrm{mR} 1 \mathrm{r} 2$ and $\mathrm{mR} 1 \mathrm{r} 4$ also produced phosphorylation of Dap12. We concluded that the transmembrane and cytoplasmic region of mCD200Rs dictated their state of glycosylation. In addition, we were able to show that both mCD200R1 and mCD200R2 bound CD200 as ligand with functional consequences (tyrosine phosphorylation) for downstream signaling.

\subsubsection{Further Intracellular Events Occurring Downstream} of CD200:CD200R. Attention has also focused on other intracellular changes which occur in the relatively immediate aftermath of CD200R1 engagement by CD200. A fusion protein CD200-Ig induced the plasmacytoid subset of splenic DCs (pDCs) to express the enzyme IDO, which initiates a tolerogenic pathway of tryptophan catabolism $[38,39]$. Those same pDCs were then shown to be capable of suppressing antigen-specific responses in vivo when transferred into recipient animals. IDO induction in pDCs through CD200R1 engagement required type I interferon receptor signaling, but autocrine production of IFN $\alpha$ was not solely responsible for all of the effects of CD200R1 engagement.

Using murine peritoneal macrophages it was shown that the IFN $\gamma$ and IL-17-stimulated cytokine secretion was inhibited by CD200R1 engagement, although surprisingly LPS-stimulated responses were apparently unaffected, unlike results reported elsewhere [40]. Tetanus toxoid-induced secretion of IL-5 and IL-13 from human PBMCs was also inhibited by CD200R1 agonists, but the effect was dependent upon cross-linking the CD200R1 on monocytes, but not on CD4 T cells, although CD200R1 is expressed on subsets of T cells [41]. As discussed in more details in the following, one of the earliest reported immunomodulatory effects of overexpression of CD200 in vivo was reported to be an alteration in the cytokine production profile following alloactivation, with preferential production of IL- 4 and IL-10 at the expense of IFN $\gamma$ and IL-2 [42].

Sato et al. [43] analyzed the mechanisms(s) whereby CD200R1 expressed on dendritic cells (DCs) led to fine tuning of chronic graft-versus-host disease (cGVHD) following allogeneic hematopoietic stem cell transplantation (alloHSCT). DCregs generated from bone marrow in vitro (BM-DCregs) expressed an alternate CD200R (CD200R3), resulting in a suppressive function in an antigen-specific CD4 T-cell response. Importantly, CD49 ${ }^{+} \mathrm{CD} 200 \mathrm{R} 3^{+}$cells were similar in phenotype and function to classical BMDCregs, and, like the latter, adoptively transferred protection from cGVHD to mice after alloHSCT. Protection was associated with development of antigen-specific anergic CD4T cells and with $\mathrm{CD} 4^{+} \mathrm{CD} 25^{+} \mathrm{Foxp} 3^{+}$Tregs, while depletion of $\mathrm{CD} 9^{+} \mathrm{CD} 200 \mathrm{R}^{+}$cells before alloHSCT enhanced cGVHD. Induction of Tregs following CD200:CD200R interactions is, as will become evident in the following, a recurrent theme in CD200R-induced immunoregulation.

The CD200R pathway has also been implicated in homeostatic control of apoptosis-derived self-antigens. Following induction of apoptosis in murine DCs, CD200 expression was markedly increased by both p53- and caspase-dependent pathways. The increased expression on apoptotic DCs in turn decreased proinflammatory cytokine production in response to self-antigens in vitro and was required for UVB-mediated tolerance to haptenated self-proteins in vivo [44].

\section{Characterization of Mice Genetically Engineered to over/underexpress CD200/CD200R}

2.1. Phenotype of Mice Lacking Expression of Functional CD200 (CD200KO). The first reported CD200KO mouse (C57BL/6 background) was found to have a normal appearance, fertility, and lifespan [45]. CD200 expression was absent in neurons in the CNS and on endothelial cells, B cells, and follicular DCs in the spleen. There was a relative increase in splenic $\mathrm{CD} 1 \mathrm{~b}^{+}$cells (a population which normally does not express CD200), along with relative overexpression of the tissue macrophage marker F4/80. In addition, higher levels of the immunotyrosine-activating motif (ITAM)containing intracellular protein DAP12 were found in the spleen marginal zone, as well as evidence for phenotypic changes of microglia in the brain, suggestive of increased endogenous activation. Since CD200R1 is expressed on macrophages, the authors concluded that in the absence of CD200 expression there existed a state of tonic activation of myeloid cells [45]. This inference was supported by additional studies in the same mice. In the first, using a facial nerve transection model [46], earlier microglial activation following surgical insult was seen in the CD200KO versus controls (peak incidence at $\mathrm{d} 4$ versus $\mathrm{d} 7$ after surgery). In a myelin oligodendrocyte- (MOG-) induced experimental allergic encephalomyelitis (EAE) model, disease onset also occurred earlier than in controls, while in a collagen-induced arthritis (CIA) model the normally resistant C57BL/6 mouse was now found to be susceptible to disease induction [45, 
47]. In studies from other groups, in this case of retinal microglia which are normally resistant to activation by LPS in part at least as a result of conditioning by endogenous TGF $\beta$ [48], it was reported that in the CD200KO mouse increased activation of the microglial cell compartment with accelerated onset of experimental autoimmune uveoretinitis (EAU) occurred, without an increase in overall disease severity [49]. The same study concluded that CD200 may play a role in maintaining the migration potential of human microglial cells. Taken together, these data formed the basis of the notion that CD200:CD200R interactions function primarily as an added inhibitory control mechanism to prevent potentially damaging proinflammatory myeloid cell activity in vulnerable tissues.

Rijkers et al. have characterized the potential role of CD200R1 expression on lymphocytes (in human/mouse) rather than its role as a regulator of myeloid function, noting differential expression on human and mouse T-cell subsets [50]. In both species, $\mathrm{CD} 4^{+} \mathrm{T}$ cells were observed to express higher amounts of CD200R1 than $\mathrm{CD} 8^{+} \mathrm{T}$ cells, with the greatest amounts of CD200R1 expressed on memory cells and upregulation of expression on both $\mathrm{CD}^{+}$and $\mathrm{CD}^{+} \mathrm{T}$ cells after stimulation in vitro. Interestingly they also observed CD200R1 expression on human and mouse $B$ cells, with highest expression on human tonsillar memory B cells and plasmablasts. Despite this, they confirmed that CD200KO mice had no discernible abnormalities in the lymphocyte compartment and had normal B cell responses on antigenic challenge, and thus the functional implications of CD200R1 expression on B cells remain unclear.

More recently a newly derived CD200KO mouse has been characterized on both a C57BL/6 and BALB/c background $[51,52]$. Again no obvious differences in fertility or overall appearance, cell/tissue phenotype was seen in comparison with wild-type mice (RMG, unpublished). These mice rejected organ allografts more vigorously than littermate controls [51] and resisted metastatic growth of breast cancer cells (to draining lymph node) following implantation into the mammary fat pad [52]. These data have been interpreted to imply an important role for CD200 expression in homeostatic regulation of immunity, while the mechanism(s) whereby such effects are achieved have yet to be elucidated.

Provocative data has also been reported suggesting a functional role for CD200:CD200R interactions in influencing bone development [53]. Osteoclasts, important mediators of bone loss leading to osteoporosis, are CD200R1 $1^{+}$. Osteoclasts from $\mathrm{CD} 200 \mathrm{KO}$ mice differentiate at a reduced rate, with decreased activation of the NF- $\kappa \mathrm{B}$ and MAP kinase signaling pathways downstream of RANK, a receptor playing a key role in osteoclast differentiation. A soluble form of CD200 rescued macrophage fusion to form osteoclasts and macrophage activation downstream of RANK, while a soluble form of CD200R1 prevented this. CD200KO mice contained fewer osteoclasts and accumulated more bone than wt animals. The importance of CD200 expression to bone development has also been investigated using a 2-dimensional and 3-dimensional culture systems, and monitoring expression of a number of mRNAs as well as growth of bone nodules and $\mathrm{TRAP}^{+}$cells in culture, as surrogate markers for preferential osteoclastogenesis versus osteoblastogenesis [54]. These data favored a model in which osteoblast expression of CD200 delivered signals (through CD200R1) to attenuate activity in osteoclasts and promote expression of mRNAs associated with bone formation [55]. In support of this hypothesis, in a follow-up study in which cells were cultured under microgravity conditions in space orbit, preferential expression of CD200 (using CD200 ${ }^{\text {tg }}$ cells) overcame the increased osteoclastogenesis seen under microgravity conditions [56].

Other studies, described in more details in the following, have used CD200KO mice to explore the importance of CD200:CD200R interactions to resistance to (influenza) viral infections $[57,58]$ and in cancer growth.

\subsection{Phenotype of Mice Overexpressing CD200 (CD200 ${ }^{t g}$ ).} An alternative tool to investigate the effects of CD200 on immune regulation has been to use a CD200 ${ }^{\text {tg }}$ mouse, first described in 2005 [59], with minor modifications which improved inducible expression (by doxycycline) without increased background expression levels reported in 2009 [60]. These mice were engineered with a nontissue-restricted promoter, and thus the transgene is overexpressed in multiple tissues of the mice following doxycycline induction. In terms of fertility, general health, and lifespan, there were no obvious differences from wild-type mice. Importantly, no evidence for increased malignancy or susceptibility to chronic infectious disease/mortality has been seen in mice maintained on doxycycline for long-term $\mathrm{CD} 200^{\text {tg }}$ expression for greater than 20 months when compared with littermate controls (Yu and Gorczynski, unpublished). No significant differences were observed in different cell subsets implicated in host resistance in these mice, with/without transgene induction [59].

Despite the lack of evidence for significant phenotypic differences as determined by the measures described, host resistance to allogeneic transplantation and tumor growth was altered dramatically in CD200 ${ }^{\text {tg }}$ mice on both a BL/6 and BALB/c background [52,60,61]. Graft rejection was decreased, though once grafts were established ongoing transgene expression was not necessary to suppress rejection [60]. In addition, both local and distant (metastatic) growth of murine breast tumor cells (EMT6) was increased in $\mathrm{CD} 200^{\text {tg }}$ mice $[52,61]$. Tissue allografts overexpressing a CD200 transgene were not rejected as rapidly as control allografts in nontransgenic mice [62], while tumors overexpressing CD200 (EMT6 ${ }^{\mathrm{CD} 200}$ ) grew more rapidly and metastasized at higher frequency than did control tumor cells in nontransgenic mice [52]. These combined data add further weight to models which suggest that expression of CD200 plays a key role in modulating immune responses important in different aspects of host resistance mechanisms.

\subsection{Phenotype of Mice Lacking Expression of Functional} CD200R1 (CD200R1KO). A CD200R1 KO mouse was described by Boudakov et al. in 2007, and it was noted again that there was no obvious phenotype associated with loss of expression of the major inhibitory receptor for CD200 
[63]. Mice remained fertile, with normal weight, lifespan, and no obvious changes in cell subsets. This contrasts with evidence for increased endogenous activation of CD200R $1^{+}$ myeloid cells reported in mice lacking CD200 [45], which was thought to represent an effect of loss of homeostatic regulation by CD200:CD200R1 in these mice. No equivalent changes in expression of CD200 expression were found for any cell subset/tissue in the CD200R1KO mouse (Boudakov, unpublished).

In contrast to the lack of phenotypic changes in CD200R1KO mice, these animals were unlike their wildtype (wt) counterparts in multiple tests of immunological function. Allografts into CD200R1KO were not prolonged by infusion of an exogenous excess of CD200Fc [63], nor indeed were alloresponses or inflammatory responses provoked by LPS in vitro suppressed by the same molecule [24]. These data were taken to infer that the CD200:CD200R1 axis played a prominent role in attenuation of inflammation, and that this, as well as other effects on acquired immune responses, was responsible for the functional changes measured in CD200R1KO mice [64].

Despite the controversy concerning the importance of CD200 as a ligand for alternate CD200Rs $[6-8,64,65]$, the CD200R1KO mice have proven to be a valuable tool in studies which have implicated a role for CD200 interaction with such receptors in regulating immune responses. Evidence has accumulated to suggest that such alternate CD200Rs, expressed preferentially on myeloid cells, deliver signals which regulate dendritic cell development and in turn alter maturation/differentiation of Foxp $3^{+}$regulatory $\mathrm{T}$ cells, thus leading to attenuation of immune responses implicated in graft rejection $[36,66]$. These functional activities reamin intact in CD200R1KO mice [36]. To date, however, mice lacking either all CD200Rs or only alternate CD200Rs (i.e., expressing only CD200R1) have yet to be derived, and definitive studies addressing the natural in vivo role of CD2000R1 versus alternate CD200Rs are thus still to be performed.

\section{A Role for CD200:CD200R in Regulation of Immune Responses}

A great deal is known about the cell surface molecules which integrate signaling at the surface of lymphocytes, in particular $\mathrm{T}$ cells. In contrast, although macrophages play a crucial role in host defence mechanisms, comparatively little is known concerning the nature of the cell surface interactions that control their activity and function, in part at least a reflection of the acknowledged functional and phenotypic heterogeneity of this population $[13,67,68]$. Nevertheless, a large body of evidence has now been built which implicates a critical role for CD200:CD200R interactions in this process. Control of expression of CD200 at other sites, in this case on endothelial cells, is also reported to play a role in regulation of cell migration and adhesion of $(\mathrm{T})$ lymphocytes in vascular beds, although not of macrophages in the same sites [69]. Endothelial CD200 expression was reported to be quite variable, with weak expression in most arteries and far greater expression in arterioles, veins, and venules, as well as on fenestrated capillaries. The levels of expression were altered following exposure to LPS, an effect entirely consistent with independent data using standard molecular tools, including chromatin immunoprecipitation (ChIP) assays with antibodies against NF- $\kappa \mathrm{B}$ p65, STAT1, and IRF-1 which suggested that IFN $\gamma$ and TNF $\alpha$ could induce CD200 expression through a $5^{\prime}$ upstream enhancer and that NF- $\kappa$ B, STAT1, and IRF-1 played pivotal roles in this process $[70,71]$. The failure of macrophages to adhere may reflect, at least in part, an effect of CD200-triggered antagonism of CD200R1-facilitated adhesion [69].

3.1. The Biological Significance of Multiple Members of CD200R Family. As noted already, several members of the CD200R family have been described in mouse (CD200R15) and at least two in man (CD200R1/R2), although there is controversy concerning the importance of CD200 as the natural ligand for members besides CD200R1 [6-8]. Many leukocyte membrane proteins contain one or more IgSF domains, with the dominant form, like CD200/CD200R, having two Ig domains which bind ligand via the Nterminal Ig domain [72]. Viral homologues of CD200, thought to have been acquired from infected host cells since IgSF domains are rare in viruses, have been identified in the Herpesviridae and Poxviridae families [72]. These viruses have become adapted to coexist asymptomatically with their host, and the CD200-related molecules they express inhibit macrophage function following interaction with CD200R1; thus human herpesvirus $8 \mathrm{~K} 14$ protein downregulates macrophage activation through CD200R1, as does cytomegalovirus e127 Protein and myxoma virus M141R [73-75]. Thus one explanation for the origin of alternate CD200Rs is that they evolved as activation receptors to counter pathogen-induced inhibitory responses mediated by CD200R1, as is apparently the case for other DAP12pairing receptors [76]. An alternative hypothesis suggests that fine-tuning by activating/inhibitory CD200Rs reflects not their use of different ligands but their expression on different cell subsets $[6,25,64]$.

3.2. Regulation of Allergic Inflammatory Disorders by CD200:CD200R. Mast cells (MCs) and basophils are relatively ubiquitous to most body tissues, where they play a key role in clearing immune complexes and complementopsonized particles. These cells also respond to microbes and other mediators and promote inflammatory responses and have been suggested to "fine tune" acquired immune responses through a number of mechanisms, including, but not limited to, interactions with DCs, T and B lymphocytes, and release of cytokines and chemokines [77]. Mast cells themselves express an antigen-specific response following cross-linking of surface-bound IgE molecules, leading to release of granule contents including histamine and serine proteases, effector molecules of allergic and immediate hypersensitivity reactions. Zhang et al. showed that such degranulation of MCs which have bound TNP-specific IgE by TNP-KLH was inhibited by simultaneous binding of CD200 
to CD200R1 on the mast cell surface, along with secretion of IL-13 and TNF $\alpha[31,78]$. These authors also showed inhibition of degranulation in human mast cells expressing normal levels of CD200R which were treated with an agonist antibody to stimulate CD200R signaling, and this effect was further enhanced by concomitant CD200 engagement.

In vivo testing in a murine model of passive cutaneous anaphylaxis revealed that inhibition in vivo by CD200R1 cross-linking was much more sensitive than that seen in vitro, perhaps reflecting a higher constitutive expression of CD200R1 on mast cells in vivo compared with cells maintained in culture, and/or the existence of other cellcell interactions in vivo which could lower the threshold for CD200R1-mediated suppression. The data from these in vivo studies were taken to imply a potential clinical utility for CD200:CD200R1 in regulation of allergic inflammatory disease.

\subsection{Regulation of Transplant Rejection by CD200:CD200R Interactions}

3.3.1. The Importance of Host versus Graft CD200/CD200R Expression on Survival. A functional role for CD200 in regulation of immunity was first proposed following studies in a renal allograft model in mice, in which it was observed that animals receiving portal vein pretransplant transfusion showed prolonged graft survival in association with CD200 overexpression, while neutralizing antibodies to CD200 abolished this effect [79]. Subsequent further "proof-ofprinciple" studies confirmed that soluble CD200Fc, lacking complement fixing or FcR binding regions, was a potent immunosuppressant which prolonged both allo- and xenograft survivals $[20,80]$. Following identification of heterogeneity in the CD200R family [7, 64], subsequent studies, making liberal use of in vitro MLC responses as a surrogate marker for suppression of alloimmunity, focused on the mechanism(s) by which CD200:CD200R could prolong graft acceptance. CD200 interactions with CD200R1 induced $\operatorname{Tr} 1$ essential for initiation of induction of suppression of graft rejection, while in contrast, interactions with CD200R2 on myeloid cells (DC precursors) altered development of the latter such that populations of "tolerogenic DCS" matured which could induce Foxp $3{ }^{+}$Tregs prominently involved in maintaining suppression of graft rejection $[7,65,81,82]$.

Mice overexpressing a CD200 transgene under control of a doxycycline-inducible promoter $\left(\mathrm{CD} 200^{\mathrm{tg}}\right)$ [83], or with homozygous deletion of CD200R1 [63], were used to confirm a crucial role for CD200:CD200R interactions in suppression of graft rejection. Even grafts from CD200 ${ }^{\text {tg }}$ mice were rejected less vigorously in control (wt) recipients, and, as expected, graft rejection was not prolonged in CD200KO mice [66]. The same CD200tg and/or CD200KO or CD200R1KO mice were used to establish an important role for both CD200:CD200R1 and CD200:CD200R2 interactions in this transplant model $[36,66]$. In CD200 ${ }^{\mathrm{tg}}$ mice once graft tolerance was established persistent overexpression of CD200 was not necessary to avoid rejection, unless an exogenous insult (in the context of inflammation induced by LPS administration) occurred. In these cases, unless overexpression of CD200 was maintained, the previously accepted grafts were rejected [60]. CD200 ${ }^{\text {tg }}$ expression in cardiac and/or skin grafts prolonged graft survival in wt recipients, with no such prolongation in CD200KO mice. However, CD200KO grafts did survive in CD200 ${ }^{\text {tg }}$ recipients. Similar studies using grafts from CD200R1KO mice suggested that CD200R1 expression within the graft tissue was essential for prolongation of graft survival. Additional studies explored changes in mRNA expression profiles in skin grafts transplanted from CD200KO, CD200 ${ }^{\text {tg }}$, and CD200R1KO mice to wt or CD200 ${ }^{\text {tg }}$ mice. The question asked was whether intragraft expression of CD200 and/or CD200R1 was essential to produce equivalent changes in gene expression and graft infiltrating cells if CD200tg recipients, overexpressing CD200 independent of graft expression, were used instead of wt mice $[60,84,85]$. These data confirmed that both CD200 and CD200R1 expressions within both the host and graft played a role in increasing graft survival on allotransplantation. A model has been proposed in which CD200:CD200R interactions, both locally within the graft and systemically in the host, induced overexpression of mRNAs, including those encoding a number of mast cell genes as well as IL-9, IL-35, and chemokines/chemokine receptors associated with attraction of Foxp $3^{+}$Tregs. Grafts in $\mathrm{CD}_{200^{\mathrm{tg}}}$ mice showed mast cell infiltration without degranulation, which was hypothesized to be dependent upon CD200 engaging CD200R1 on mast cells to suppress degranulation $[31,84]$. Consistent with this hypothesis, in grafts from CD200R1KO donors, $>90 \%$ degranulation of MCs was observed. Degranulation was attenuated in CD200KO grafts in the presence of host overexpression in CD200tg mice, which was postulated to reflect the effect of a soluble circulating form of CD200 which was detectable in such animals [51].

As commented upon earlier, stopping CD200 transgene induction following initial establishment of CD200 ${ }^{\text {tg }}$ grafts into $\mathrm{CD} 200^{\text {tg }}$ recipients did not cause inevitable graft rejection, implying that CD200 overexpression was not needed indefinitely. However, infusion of anti-CD200 at any time after transplantation led to swift rejection of all grafts [60]. This was taken to imply that only endogenous CD200 expression, not transgenic overexpression of CD200, was necessary for tolerance maintenance. In CD200 ${ }^{\text {tg }}$ mice, graft infiltration by nondegranulating MCs and Foxp $3^{+}$Treg was associated with increased graft survival, along with increased CCR4/CCL22 and IL-35 expression (implicated in Treg migration/maturation, resp. [84, 85] and IL-9 (a MC growth factor)).

The relative importance of other factors induced following CD200:CD200R engagement in promoting graft acceptance has been elucidated using 2 models, namely, (i) using CD200KO, CD200R1KO, CD200 ${ }^{\text {tg }}$, or CD200 ${ }^{\text {tg }}$ CD200R1KO allografts transplanted into sets of similar primary recipients and (ii) using CD200 ${ }^{\text {tg }}$ or wt allografts harvested from CD200 ${ }^{\text {tg }}$ or wt mice and retransplanted to secondary wt recipients. In both models graft survival, MLC responses, and graft tissue gene expression have been assessed. Typical data for primary cardiac transplants from $\mathrm{BL} / 6$ mice to $\mathrm{BALB} / \mathrm{c}$ 
TABLE 1: CD200g, CD200R1KO, and CD200R1KO·CD200tg graft survival in wt/CD200 ${ }^{\text {tg }}$ mice.

\begin{tabular}{|c|c|c|c|}
\hline $\mathrm{BL} / 6$ donor mice ${ }^{\mathrm{a}}$ & $\mathrm{BALB} / \mathrm{c}$ recipients ${ }^{\mathrm{b}}$ & MST (with range) ${ }^{\mathrm{c}}$ & Percentage of grafts surviving $>75 d$ \\
\hline Control (wt) & wt & $9.4(7-12)$ & $0 \%$ \\
\hline Control (wt) & CD200tg & $48.8(19-129)^{* *}$ & $50 \%$ \\
\hline CD200KO & wt & $7.6(7-11)$ & $0 \%$ \\
\hline CD200KO & CD200tg & $42.2(15-121)^{* *}$ & $40 \%$ \\
\hline CD200R1KO & wt & $8.8(7-13)$ & $0 \%$ \\
\hline CD200R1KO & $\mathrm{CD} 200^{\mathrm{tg}}$ & $32.4(17-88)^{*}$ & $20 \%$ \\
\hline $\mathrm{CD} 200 \mathrm{R} 1 \mathrm{KO} \cdot \mathrm{CD} 200^{\operatorname{tg}}$ & wt & $11(9-25)$ & $0 \%$ \\
\hline $\mathrm{CD} 200 \mathrm{R} 1 \mathrm{KO} \cdot \mathrm{CD} 200^{\mathrm{tg}}$ & CD200tg & $33(19-97) *$ & $30 \%$ \\
\hline
\end{tabular}

${ }^{\mathrm{a}, \mathrm{b}}$ Cardiac grafts were obtained from individual donors (all on doxycycline, DOX, for 7 days to induce transgene expression) and transplanted to 10 recipients/group (all maintained on DOX).

${ }^{c}$ Grafts were palpated daily for evidence of rejection; MST indicates mean (graft) survival time in days. $* P<0.05$ compared with 1 st row; $* * P<0.05$ compared with CD200R1KO or CD200R1KO·CD200"g grafts transplanted to CD200tg (rows 6 and 8).

recipients are shown (MST indicates mean (graft) survival time) in Table $1[62,66]$.

Primary grafts from CD200KO or CD200R1KO mice, like wt grafts, were rapidly rejected in wt mice (Table 1 ). A trend to greater survival of CD200R1KO $\cdot \mathrm{CD} 200^{\text {tg }}$ grafts compared with CD200R1KO grafts was seen in wt mice, but differences were not significant, unlike the increased survival seen in wt mice with CD200 ${ }^{\text {tg }}$ grafts [60], implying that intragraft expression of both CD200 and CD200R1 was important to enhance survival in wt mice. Using CD200 ${ }^{\text {tg }}$ recipients, different results were seen. All grafts survived longer than when into wt recipients $(P<0.05$, Mann-Whitney $U$-test (Table 1$)$ ). CD200R $1^{+}$expressing grafts survived longer than CD200R1KO grafts in CD200 ${ }^{\text {tg }}$ mice, suggesting that in recipients overexpressing CD200, intragraft expression of CD200R1 was important for optimal graft survival. Intragraft overexpression of CD200 failed to improve survival in CD200R1KO mice [63]. Data from MLC cultures comparing attenuation of CTL responses from grafted mice were consistent with the relative graft survival in the different groups of donors/recipients [66].

In secondary wt recipients of retransplanted primary CD200 ${ }^{\text {tg }}$ grafts, cells in draining lymph nodes (DLN) showed antigen-specific decreased induction of CTL to BL/6 targets compared to DLN of recipients of wt grafts, with evidence for regulatory $\mathrm{CD}^{+}$, cells [62]. Augmented expression of many mRNAs including TGF $\beta$ and PD-1 (PD-L1/PD-L2) was seen in grafts into secondary recipients relative to primary recipients, with enhanced expression of mRNAs encoding CCL22/CCR4, the subunits of IL-35 (IL-12a/IL27b), and IDO [62]. IL-35 and IDO are implicated in expansion of antigen-specific inducible Foxp $3^{+}$Tregs (iTregs) $[86,87]$, while IDO itself is thought to be produced following CCL22 activation of CCR4 on DCs [88]. As IDO levels fall, iTregs alter their functional profile towards Th17-type cells, contributing to chronic inflammation [87].

The correlation between graft survival and graft infiltration by nondegranulating mast cells thus also seems to be correlated with mechanism(s) involving Tregs [89]. Mast cell-derived IL-6, along with OX40L:OX40, promotes a switch from Treg to Th17 differentiation, with chronic inflammation ensuing [90]. Consistent with this proposed role for mast cells, rat heart rejection is more severe using mast cell-deficient donor hearts [91], and both intragraft and systemic mast cell degranulation causes a transient loss of Treg suppressor activity and acute rejection of tolerant allografts [92]. CD4 ${ }^{+} \mathrm{T}$ cells produce IL-9, a mast cell growth and activation factor crucial for mast cell recruitment to and activation in, tolerant tissue, under control of TGF $\beta$ [93-95], and IL-4, enhancing the function of Foxp $3^{+}$Treg cells [96]. Local increases in stem cell factor, which synergize with IL-9 in mast cell differentiation, are reported in lung transplant recipients [97]. In mouse mast cell-derived IL-10 prolongs IL-9 mRNA stability [98], which may contribute to how IL-10 (possibly derived from Tr1) prolongs graft survival [99]; expression of IL-9 and IL-10 is increased in CD200 ${ }^{\text {tg }}$ recipients [60].

Rejection and increased degranulation of mast cells were also found to occur in grafts in $\mathrm{CD} 200^{\text {tg }}$ mice receiving a natural antagonist of CD200, lacking an NH2-terminal domain, CD200tr [100]. Both effects were lost after infusion of sodium cromoglycate, a mast cell stabilizer, in vivo [84]. It was suggested that activation/degranulation of mast cells, regulated by local molecules (chemokines/cytokines) [101], contributed to the effector stages of rejection [102]. Suppression of degranulation by CD200 engagement of CD200R1 on the mast cell surface, along with DC-derived IDO and IL-35 to expand graft-infiltrating Tregs [86], would then be predicted to decrease effector T-cell activation and prolong survival [31].

3.3.2. Immunosuppressive Soluble CD200 Is Increased in Posttransplant Serum. Many cell surface molecules with immunoregulatory function are also found in soluble form in serum following either release as exosomes (EX) from the cell surface or after enzymatic cleavage by membraneanchored multidomain proteins containing disintegrin and metalloprotease domains (ADAMs) $[103,104]$. The role that EXs play in cell-to-cell signaling has become of great interest given that EXs can merge with and release their contents into cells that are distant from their cell of origin [105]. Equally, EX production and content may itself be influenced by molecular signals received by the cell of origin. (As a point of clarification, EXs have also been referred 
to as microvesicles, EX-like vesicles, microparticles, and so forth, but in all discussions hereafter vesicles harvested by ultracentrifugation $(100,000 \mathrm{~g} \times 60 \mathrm{~min})$ are referred to as EXs [106]). Several studies have reported on the immunoregulatory properties of exosomes (EX) in plasma [107-109].

A soluble form of CD200, sCD200, with immunosuppressive function was found in serum after transplantation [51]. In wt mice receiving high-dose rapamycin to increase graft survival, or CD200 ${ }^{\text {tg }}$ but not CD200KO mice, increased sCD200 levels paralleled enhanced graft survival. sCD200 ${ }^{+}$sera inhibited MLCs and induced Tregs, both $\operatorname{Tr} 1$ and iFoxp $3^{+}$Tregs [51]. Preliminary studies on the nature of the sCD200 detected after transplantation (EX or soluble protein, SP), and its mechanism of action has revealed little activity in the EX fraction, with the majority of the immunosuppressive function residing with soluble protein. In preliminary studies in collaboration with the Cardiac Transplant Group at UHN (Dr. Heather Ross), a rise in sCD200 levels after transplant in patients with fewer rejection episodes has also been seen with lower levels observed in patients with rejection (unpublished data).

\subsubsection{CD200 in Maternal:Fetal Allografts and Normal Preg-} nancy. Using mice with a predisposition to enhanced fetal loss, CD200Fc was shown to attenuate fetal loss while in contrast it was increased by anti-CD200 mAb injections [110]. Extension of these studies to humans showed that placental trophoblast from successful human pregnancies as predicted expressed CD200 [5]. Further support for a role for CD200 in pregnancy came from data showing that loss of cell surface CD200 on stored human leukocytes was correlated with their inability to suppress fetal loss in patients treated for recurrent abortion [111]. From experiments seeking to understand mechanism(s) whereby intravenous immunoglobulin (IVIG) might also contribute to improved pregnancy outcome in cases of recurrent fetal loss, it was suggested that one mechanism might involve CD200 (present in IVIG) modulating NK cell activity [112].

In another model of fetal loss in rodents provoked by inflammatory stimuli, CD200 was again found to exert a protective influence [113]. Lipopolysaccharide (LPS) which acts via tlr4 to promote Th1 cytokine secretion and abortions is an essential cofactor in spontaneous abortion in the CBAxDBA $/ 2$ model and in stress-triggered abortions. In this model, C3a, C5a, and fgl2 prothrombinase participate in triggering the inflammation which ultimately terminates embryo viability. Since the prothrombinase fgl2 has been shown to generate C5a, it was predicted that LPS-driven abortions (which required fgl2) would be independent of C3 [114], but C5 dependent. Once again, overexpression of CD200 was shown to protect from pregnancy failure [113].

3.3.4. "Designer" Molecules with CD200 Epitopes as Novel Immunosuppressants. A potential limitation to the clinical use of CD200Fc for treatment of cardiac graft rejection and indeed in other clinical scenarios lies in its size $(\sim 48 \mathrm{KDa})$ and its pleiotropic effects, likely related to engagement of different CD200Rs [64]. Studies in mouse transplant models support a model in which CD200:CD200R1 engagement early after transplant enhances induction of Tr1 cells, dependent upon IL-10 for their suppressive function [64], while later engagement of CD200R2 (on DC precursors) favours differentiation of tolerogenic DCs which promote development of Foxp $3^{+}$Tregs able to maintain graft survival [36]. This has focused interest on characterizing unique domains of CD200 with agonist and/or antagonist activity for R1/R2 using synthetic CD200-derived peptides. The Nterminal region of CD200 and CD200R is key for interactions to inhibit graft rejection and regulate inflammation $[22,24$, $115,116]$. Preliminary studies have suggested that discrete CD200 peptides can be synthesized with preferential activity for these different CD200Rs, which may have clinical utility [24].

Since CD200:CD200R1 interactions increased TGF $\beta$ expression and TGF $\beta$ is a key molecule in induction/maintenance of Treg suppression [117], it was hypothesized that a genetically engineered hybrid molecule, CD200(Gly) 6 TGF $\beta$, linking TGF $\beta$ to a ligand for CD200R1, might prove to be a potent immunosuppressant. The hybrid molecule was superior in this regard to a combination of CD200 or TGF $\beta$, with activity dependent on engaging CD200R1 on APCs and TGF $\beta$ RII on $\mathrm{T}$ cells [118]. Current approaches are investigating the use of novel hybrid molecules including discrete peptides of CD200 linked genetically to TGF $\beta$ as immunosuppressants.

3.4. Regulation of Autoimmune Disease by CD200:CD200R Interactions. Despite the evidence that CD200:CD200R interactions are important modulators of immunological nonresponsiveness and that CD200 is expressed within the thymus and in other organs of lymphopoiesis, central tolerance is not compromised in either CD200KO or CD200R1KO mice. In neither case have mice been reported to succumb to spontaneous autoimmune disease. Nevertheless, CD200 is clearly implicated in peripheral tolerance, as documented from data in several systems. Presentation of antigens from apoptotic cells by DCs is thought to be crucial for maintenance of self-tolerance [119], with defects in this process resulting in autoimmunity [120]. Increased CD200 expression by apoptotic cells, which decreased proinflammatory cytokine production, was critical for tolerance induction in a contact hypersensitivity model [4]. Similarly, CD200:CD200R interactions have been proposed to bias development of indoleamine 2,3dioxygenase- (IDO-) producing DC subsets [39, 121], and altered tryptophan metabolism by this enzyme has been associated with maintenance of tolerance, perhaps through regulation of induction of Tregs [38].

CD200Fc is not only successful in suppressing transplant rejection [20] but also potently inhibits collagen-induced arthritis (CIA) in rodents [122]. This observation is consistent with evidence from the CD200KO mouse suggesting increased susceptibility to induction of autoimmune disease (experimental allergic encephalomyelitis, EAE, a murine model of multiple sclerosis, MS) [45]. Cross-linking antibodies to CD200R1 also attenuates CIA [123], along with 
altered expression of cytokines associated with inflammatory pathology in this model. These observations were confirmed in independent studies [124] which compared CD200Fc with TNF inhibition (the current method of choice for refractory RA patients in the clinic). Inhibition mediated by CD200Fc in this system was comparable to that achieved by TNFRFc [125]. Recently Chen et al. (personal communication) have established the importance of the CD200:CD200R axis in regulation of intestinal inflammation in a model of dextran sulfate-induced colitis in mice. CD200R1KO mice showed exquisite sensitivity to this chemical, with death in $>50 \%$ of mice by day 20 , while $\mathrm{CD} 200^{\mathrm{tg}}$ mice were fully protected. A correlation has been observed between these different susceptibilities and histologic/molecular profiles in intestinal tissue in these two combinations.

CD200 expression has also been found to regulate inflammation in the hair follicles of the skin $[4,126]$. CD200 is expressed on Langerhans cells (LCs) and keratinocytes (KCs) in mouse epidermis, and skin in CD200KO mice is susceptible to hair follicle inflammation and immune-mediated alopecia, suggesting that CD200:CD200R interactions attenuate perifollicular inflammation and may protect epidermal stem cells from autoimmune destruction. This is consistent with other data showing an effect of CD200 expression on UV-mediated tolerance to skin hypersensitivity [44].

A number of studies have addressed the importance of CD200-mediated suppression in autoimmune uveitis [127] and uveoretinitis [49, 128, 129]. In one such study, an agonist monoclonal rat anti-mouse CD200R1 antibody was used to suppress IFN $\gamma$-mediated nitric oxide (NO) and interleukin-6 production. In CD200KO mice increased numbers of retina-infiltrating macrophages with increased NO responses were observed both naturally [130] and during induction of experimental autoimmune uveoretinitis (EAU), which was attenuated by suppression of macrophage activation with anti-CD200R1, despite maintained T-cell proliferation and IFN $\gamma$ production [129], using a similar model system to explore tolerance to EAU induced by a single exposure to inhaled retinal antigen 10 days before immunization. It was found that despite the earlier onset of EAU in sham-tolerized, CD200KO mice, disease incidence and severity were measurably reduced compared with those seen in wild-type mice, and protection was long-lasting (>28 days). Attenuation of disease progression and tolerance in CD200KO mice was correlated with increased Th2type cytokine production by antigen-challenged splenocytes. While unexpected, the reduced overall disease and enhanced tolerance in the CD200KO mice in this novel system were taken to suggest that in the absence of (default) inhibitory CD200R1 signaling, alternative routes of immunoregulation were prominent, including dominant Th2 activation and/or altered negative signaling by other myeloid cell-expressed regulatory molecules.

A final recent study, in this case in systemic lupus erythematosus patients, has investigated a role for both membrane-bound and soluble forms of CD200 in suppression (see data above on sCD200 in transplant patients and in the following in cancer) [131]. Serum CD200 levels were detected by ELISA, and the expression of CD200 and CD200R1 by $\mathrm{CD}^{+} \mathrm{T}$ cells and DCs was examined by flow cytometry, using both SLE patients and healthy controls. In SLE patients, the number of CD200 ${ }^{+}$cells and the level of sCD200 were higher than in controls, while the expression of CD200R1 by $\mathrm{CD}^{+}{ }^{-} \mathrm{T}$ cells and DCs was decreased. Early apoptotic cells expressed increased CD200 [44], which contributed to their diminished binding and phagocytosis by DCs in SLE. CD200R $1^{+} \mathrm{CD} 4^{+} \mathrm{T}$ cells incubated with $\mathrm{CD} 200 \mathrm{Fc}$ in vitro showed reduced differentiation of Th17 cells and attenuation of the defective induction of $\mathrm{CD}^{+} \mathrm{CD} 25^{\text {high }} \mathrm{FoxP}^{+} \mathrm{T}$ cells by $\mathrm{TGF} \beta$ in SLE patients. In contrast, blockade of CD200:CD200R1 interactions (non-cross-linking anti-CD200R1) augmented $\mathrm{CD}^{+}{ }^{+} \mathrm{T}$-cell proliferation. The authors concluded that the abnormal CD200:CD200R interactions seen and the effect this has on T-cell regulation, may represent contributory factors in the immunologic abnormalities characteristic of SLE.

3.5. Influence of CD200:CD200R Expression on Nervous System Tissue. Along with the histomorphological evidence that CD200 is expressed in cells of the nervous system, the potential importance of this expression to homeostasis within the central nervous system was made evident from the early observations of Hoek et al. in CD200KO mice [45]. Brain tissue in these animals was found to overexpress CD200R (presumably in the absence of suppressive signals from glial tissue CD200) and to be more susceptible to induction of autoimmune encephalomyelitis, a model system used for human multiple sclerosis. Increased expression of CD200 was also seen on retinal neurons following blockade with anti-CD200R1 mAb, with increased NOS expression by retinal macrophages [132]. A detailed study showing the importance of neuronal expression of CD200 in protection from inflammatory-mediated neurodegeneration was subsequently reported by Chitnis et al. [133]. This group used as their model Wlds mice, bearing a triple repeat of the fusion gene Ube4b/Nmnat and thus expressing a phenotype of axon protection. When subject to immunization to produce conventional allergic experimental encephalomyelitis (EAE) Wlds mice have an attenuated disease course which is associated with constitutive expression of CD200 on neurons in the CNS. The receptor CD200R was expressed on microglia, astrocytes, and oligodendrocytes at equivalent levels in control and Wlds mice. However, in the presence of a blocking anti-CD200 antibody disease attenuation was lost and increased CNS inflammation and neurodegeneration were seen.

Additional studies have made a case for a role for altered CD200 expression in the regulation of normal brain aging and following ischemic insults. Thus age-related qPCR mRNA alterations in MHC class II and proinflammatory mediators (and molecules regulating these) in the hippocampus were assessed in aged (24 months) and young ( 3 months) male rats. Interestingly aged animals showed increased mRNA levels of MHC II, CD86, and IFN $\gamma$ with decreased levels of expression of mRNAs for IL-10 and CD200 mRNA, molecules that downregulate macrophage activation [134]. Matsumoto et al. [135] characterized macrophage-like cells 
accumulating in the ischemic core of rats with transient right middle cerebral artery occlusion. One week following reperfusion macrophage-like cells expressed CD200, and immunohistochemical analysis confirmed a location on the cell membrane of spherical Iba1+ macrophage-like cells with many cytoplasmic granules thought to be responsible for the suppression of $\mathrm{CD}_{200 \mathrm{R}^{+}}$myeloid cell functions in the ischemic core.

In yet another investigation into the role of CD200: CD200R in perturbed CNS pathology, evidence for altered CD200:CD200R expression (and increased inflammation) in Alzheimer's disease (AD) was reported [136]. Quantitative studies revealed decreased CD200 protein and mRNA expression in $\mathrm{AD}$ hippocampus and inferior temporal gyrus, but not cerebellum, while immunohistochemistry of brain tissue sections from both $\mathrm{AD}$ and nondemented cases revealed a predominant, albeit heterogeneous, neuronal localization for CD200. The decreased neuronal expression was predominant in those brain regions affected by AD pathology. Further studies also showed significantly decreased CD200R mRNA expression in both AD hippocampus and inferior temporal gyrus, but not in the cerebellum, with the low expression of both protein and mRNA for CD200R confirmed in cultured human microglia when compared with blood-derived macrophages. Interestingly levels of CD200R in microglia and macrophages were increased following treatment with interleukin-4 and interleukin-13, cytokines not generally detectable in brain tissue, which the authors speculated may be predictive of a role in therapy for human neurodegenerative diseases.

3.6. Role of CD200 Expression in Regulation of Infectious Disease. Given the hypothesis that CD200 plays an important physiological role as a natural "downmodulator" of inflammatory reactions, it is no surprise that various groups have sought to explore the possibility that expression of CD200 may regulate infectious processes. Airway macrophages were found to express higher levels of CD200R1 than did their systemic counterparts, and CD200KO mice had more macrophage activity and enhanced sensitivity to influenza infection, with delayed resolution of inflammation and death. Agonists which could activate CD200R1 could attenuate this process in CD200KO mice [57]. This study was recently extended by Rijkers and associates [58] who confirmed that the CD200KO mice developed more severe disease, with increased lung infiltration and lung endothelium damage, following influenza infection than the wt controls. Interestingly, they found that development of disease was prevented by $\mathrm{T}$-cell depletion prior to infection, despite an increased viral load in such circumstances. They concluded that $\mathrm{T}$ cells were essential for the development of disease pathology in this model and that CD200:CD200R interactions controlled the pathology mediated by such cells.

A more subtle form of immunoregulation dependent upon CD200 expression during viral infection has also been reported [137]. As mentioned above, a prominent splice variant of CD200 exists, lacking the $\mathrm{NH}_{2}$-terminal amino acids, which has been referred to as CD200tr [100]. This splice variant is unable to induce immunosuppression following binding to CD200R1 but apparently can act as a natural competitive inhibitor of CD200, attenuating suppression mediated by the full-length molecule. In vivo studies of MHV-1 susceptible A/J mouse lung tissues found that, following viral infection, the normal mRNA expression pattern of CD200 in the lung (overexpression of CD200tr at the expense of CD200) was reversed, with the full-length transcript now the predominant one in these susceptible mice. In contrast, for MHV-1-resistant C57BL/6J mice, no change in the mRNA splicing pattern of CD200 was seen in the lung. This altered splicing after infection in the MHV-1 susceptible mice, leading to an increase in the CD200:CD200 tr ratio, was suggested to be a contributing factor explaining the increased susceptibility to MHV-1 in the A/J mice. These same studies identified an exonic splicing enhancer (ESE) located in exon 2 of CD200, which was a putative binding site for the splicing regulatory protein SF2/ASF, with deletion/mutation of the ESE site decreasing expression of full-length CD200. Increased expression of SF2/ASF was seen in A/J mice postinfection prior to any observed increase in full-length CD200, consistent with the hypothesis that the regulation of alternative splicing of CD200 following infection was mediated by SF2/ASF, though the viral proteins of $\mathrm{MHV}-1$ responsible and their mechanism(s) of action were not identified. These data suggest that viruses may escape elimination by the host's immune system not only through producing viral proteins which mimic CD200, as has been described elsewhere [73, $74,138,139]$, but also by inducing host CD200 expression and reducing expression of the antagonist CD200 $\mathrm{tr}$.

More recently, other chronic infectious conditions in which CD200:CD200R interactions seem to control pathology have been reported, namely, those associated with infection by the bacterial pathogen Salmonella enterica, or the helminth, Schistosoma mansoni [140]. A key, previously undiscovered, effect in these scenarios was the increased expression of CD200R1 on $\mathrm{CD}^{+}{ }^{+} \mathrm{T}$ cells in response to chronic infection, following infection with both Salmonella enterica, or Schistosoma mansoni, pathogens know respectively to drive predominant $\mathrm{Th} 1$ or $\mathrm{Th} 2$ responses. In vitro studies confirmed that prolonged stimulation was needed for sustained upregulation of CD200R1 and also that its expression coincided with loss of multifunctional potential in effector $\mathrm{T}$ cells during infection. This work was extended to show an association between IL-4 production and CD200R1 expression on effector T cells from humans infected with Schistosoma haematobium, changes that were in turn correlated with egg burden and infection intensity. The authors concluded that the postulated role for CD200R:CD200 in T-cell responses to helminths may have diagnostic and prognostic relevance in monitoring chronic schistosomiasis in man.

3.7. Importance of CD200:CD200R to Regulation of Response to Tumors. The first indication that CD200:CD200R interactions might be of relevance to the field of cancer biology came from studies using the mouse transplantable thymoma (EL4) in C57BL/6 mice. It was found that all manipulations which were used to attenuate growth of this tumor in mice 
were themselves inhibited by infusion of an excess of soluble CD200Fc [141]. Subsequent studies from a number of different groups confirmed that CD200 overexpression was a predictor of poor prognosis in a number of human blood malignancies, including acute myeloid leukemia (AML) [142], chronic lymphocytic leukemia (CLL) [143], and multiple myeloma [144]. In the case of AML patients recent studies have suggested that tumor overexpression of CD200 is associated with suppression of NK activity directed to leukemic cells, which may, in part at least, help account for loss of antitumor control [145]. While the majority of plasma cell myelomas express CD200, nevertheless patients with CD200- tumors had a longer event-free survival (EFS) after autologous stem cell transplantation than those with $\mathrm{CD} 200^{+}$disease [146].

The question has arisen, given this association of CD200 expression with blood cell malignancies, as to whether disruption of CD200:CD200R interactions affects normal myelopoiesis [50]. A variety of colony-stimulating factors (CSFs) are crucial for support of both lymphopoiesis and myelopoiesis, with signals from many CSF receptors mediated by the Ras signaling pathway. The adaptor molecules Dok-1 and Dok-2 are involved in myelopoiesis [147], and upon phosphorylation they inhibit the Ras signaling pathway, likely by recruiting RasGAP, which converts active RasGTP to inactive RasGDP. Mice with homologous deletion of both Dok-1 and Dok-2 develop chronic myelogenous leukemia-like myeloproliferative disease at 10-12 months of age. CD200R1 is known to recruit Dok-1 and Dok-2, and thus one speculation was that CD200KO mice might have a phenotype of altered myelopoiesis and susceptibility to leukemia. In fact no altered numbers of myeloid progenitors in the bone marrow were seen in these mice, and the cells apparently had a normal proliferative capacity, implying that the development of leukemia in the Dok-1/Dok-2 DKO mice could not solely be explained by an absence of CD200R1 signaling [50]. These observations suggest that the effects of CD200:CD200R interactions on hematopoietic malignancies likely involve more complex mechanism(s) including those involving altered regulation of inflammatory and/or immune responses.

Further studies in human CLL over the past several years have confirmed the importance of attenuation of the CD200 "suppressive signal" to improving responses to therapy. Kretz-Rommel et al. [148] used a novel xenograft NOD/SCID animal model with human immune cells and human CLL tumor cells to explore the effects of CD200 overexpression on tumor cells and of anti-CD200 Abs, on tumor growth regulated in vivo with human immune cells. Human peripheral blood mononuclear cells (PBMCs) prevented tumor growth of CD200 tumors, but not of $\mathrm{CD} 200^{+}$cells, unless anti-CD200 $\mathrm{mAb}$ was used as adjunctive therapy. Subsequent studies by the same group characterized the effect of $A b$ variants with or without effector function (IgG1 constant region (G1) or IgG2/G4 fusion constant region (G2G4), resp.), concluding that anti-CD200-G1 Abs were the most efficient at mediating Ab-dependent cellular cytotoxicity of activated $\mathrm{T}$ cells, critical cells involved in immune-mediated killing [149]. Subsequent clinical trials are now underway (Alexion Pharmaceuticals).

Other studies in human CLL [150] also used an autologous mixed lymphocyte reaction, in this instance with native and CD40 ligand- (CD40L-) stimulated CLL cells as antigen-presenting cells (APCs) to expand autologous $\mathrm{T}$ cells. T-cell proliferation was enhanced over a 3-week period using CD40L-stimulated APCs and anti-CD200 antibody, with the stimulated $\mathrm{T}$ cells developing an antigen-specific response to the CLL-associated antigen fibromodulin. The same group reported a reduction in $\mathrm{CD} 4^{+} \mathrm{CD} 25^{\text {high }} \mathrm{FOXP} 3^{+}$ $\mathrm{T}$ cells following adding of anti-CD200 antibody in vitro. Functional silencing of CD200 expression with siRNAs, or use of anti-CD200 mAbs, was also reported to augment T-cell immune responses to CLL measured by cytotoxicity or cytokine induction in MLCs using human PBMCs and CLL cells [151]. More recently, increased levels of a serum soluble form of CD200 (sCD200, see above) in CLL patients were reported, with those levels correlated with disease in association with other Rai-stage disease markers [152]. In a novel NOD $\cdot \mathrm{SCID}^{22 \mathrm{r}-/-}$ mouse model infusion of sCD $200^{\text {high }}$ serum allowed for long-term engraftment of CLL cells in multiple tissues of the mice, while absorption of sCD200 from serum abolished this effect, as indeed did treatment of recipients with anti-CD200 mAb, or OKT3 [152]. The authors concluded that both sCD200 and a subpopulation of T cells were essential for establishment and growth of CLL, at least in this xenogeneic model. Current studies are underway to characterize the nature of the sCD200 and to explore in more details the mechanism(s) responsible for control of CLL growth in vivo in NOD.SCID ${ }^{\gamma 2 \mathrm{r}-/-}$ mice.

In addition to expression of CD200 on the cell surface of hematologic tumors, it has now become apparent that CD200 is also expressed in many solid malignancies, including subsets of melanomas, breast cancer, renal cell carcinomas and ovarian tumors [153], squamous cell carcinomas [154], and, most interestingly, in the so-called cancer stem cells (CSCs) within the solid tumor [155]. In this latter case it has been proposed that CD200 expression plays a role in the ability of a CSC to escape the immune system [156]. Addition of $\mathrm{CD}_{200}{ }^{+}$, but not $\mathrm{CD} 200^{-}$solid tumor cell lines to mixed lymphocyte reactions in vitro, was found to attenuate production of Th1 cytokines, a suppression which was in turn abolished by anti-CD200 antibody [153]. Studies in melanoma patients [157] have suggested that mutations of N-RAS or B-RAF, genetic lesions present in most melanoma patients, are responsible for induction of expression of cell-surface CD200, which in turn represses DC function and prevents establishment of an effective immune response. Consistent with this hypothesis, melanoma cell lines expressing endogenous CD200 also suppressed primary T-cell activation by DCs, and shRNA knockdown of CD200 abolished this suppression.

Studies using the EMT6 mouse breast cancer line were the first to establish an unequivocal role for CD200 expression in regulation of growth of breast cancer cells in an animal model system. Tumor cells growing in control $\mathrm{BALB} / \mathrm{c}$ mice were selected for overexpression 
of CD200 on the tumor, whereas in immunocompromised/immunosuppressed mice, either NOD.SCID or $\mathrm{CD} 200^{\text {tg }} \mathrm{BALB} / \mathrm{c}$ mice, no such selection occurred [158]. Graft infiltrating cells $\left(\mathrm{GR}^{+}\right.$and $\mathrm{CD}^{+} / \mathrm{CD}^{+} \mathrm{T}$ cells) were also altered in such animals, and again, enhanced tumor growth was correlated with rising levels of sCD200 in tumor-bearing animals. A most provocative finding was that by comparing the frequency of tumor cells cloned from draining lymph nodes (DLNs) of tumor-injected mice, an important role for CD200 expression in regulation of metastatic growth, as well as of primary tumor growth, was established [52]. CD200 ${ }^{\mathrm{tg}}$ mice showed increased metastasis of tumor compared with control mice, an effect which was attenuated by anti-CD200 mAb, even in the absence of evidence for a direct effect (of anti-CD200) on tumor cells themselves. Tumor growth and metastasis were further enhanced using CD200 ${ }^{\text {tg }}$ EMT6 tumor cells, while the converse proved to be the case using EMT6 cells carrying a silencer for mouse CD200 (shRNA-transfected) [159]. Importantly and consistent with the hypothesis that CD200:CD200R interactions in this model suppress a host antitumor response able to regulate both local and distant tumor growth, CD200R1KO mice showed reduced tumor growth and metastasis, while optimal tumor immunity (and suppression of metastasis) was seen in CD200R1KO mice receiving inocula of CD200-EMT6 tumor cells [159]. This idea that CD200 expression may be relevant to regulation of tumor metastasis was confirmed independently by Stumpfova, in a skin squamous cell carcinoma study [154].

More recent studies have centered on human breast cancer and found that levels of sCD200 in patient sera were correlated with most aggressive disease and metastasis and that $>30 \%$ of human breast cancer tumors expressed CD200, with evidence for tumor infiltration by CD200R1 ${ }^{+}$ cells (Podnos, Gorczynski, and Clark-in preparation). These findings, while still of a preliminary nature, support the notion that monitoring sCD200 may provide valuable diagnostic and prognostic information in this disease and that therapies directed at interrupting CD200:CD200R1 interactions may prove to have clinical utility.

That the story concerning the effect of CD200 expression on cancer growth is not quite as simple as might be inferred from the EMT6 data and the melanoma studies discussed above is evident from at least two recent observations. In an alternative mouse breast cancer model, using 4T1 cells injected into control or $\mathrm{CD} 200^{\text {tg }} \mathrm{BALB} / \mathrm{c}$ mice, it seems that tumor growth is actually attenuated by host overexpression of CD200. This altered growth pattern is consistent with other changes suggesting that inflammatory stimuli enhance growth of this tumor (Erin et al., personal communication), in marked contrast to the effect of CD200 expression on EMT6 cells in the same animals [61]. In addition, a recent experimental mouse model has explored the role for CD200 expression in melanoma in greater details, using $\mathrm{CD}_{200}{ }^{+}$and $\mathrm{CD}^{2} 00^{-}$B16 melanoma cells. These data reported, somewhat unexpectedly, that subcutaneous injection of $\mathrm{CD} 200^{+} \mathrm{B} 16$ melanoma cells actually inhibited tumor formation and growth in $\mathrm{C} 57 \mathrm{BL} / 6$ mice but not in Rag12/2C57BL/6 mice, while iv injection of $\mathrm{CD}_{200}{ }^{+} \mathrm{B} 16$ melanoma cells inhibited tumor foci formation in the lung of both sets of mice. CD200R1 was expressed by Gr1 ${ }^{+}$myeloid cells in the lungs of these animals, and depletion of these $\mathrm{Gr}^{+}$cells or stimulation of the CD200R1 using cross-linking anti-CD200R1 antibodies in vivo also inhibited tumor foci formation in the lungs, leading the authors to conclude that in this model CD200:CD200R interactions were most relevant to inhibiting tumor formation and metastasis [160]. These independent observations, in separate model systems, point to a complexity in the effect of CD200:CD200R interaction on tumor growth, which is discussed elsewhere by Rygiel and Meyaard [161]. It is evident that, in cancers which respond differently to inflammation, the blockade of CD200 could, theoretically at least, result in either attenuated or enhanced tumor growth.

\section{Summary}

In just over a decade there has been an explosion of evidence confirming the importance of CD200:CD200R interactions in control of inflammation and immunity in a number of models of clinical significance. While there remain significant unknowns, including the mechanism(s) responsible for many of the changes seen, and even, in some cases, the nature of all of the ligands which contribute to the regulation observed, it has nevertheless proven possible to use reagents directed at interfering with CD200:CD200R to alter physiological process in vivo, in systems as disparate as allergic reactions, transplant rejection, autoimmunity, and cancer. It is somewhat of a surprise therefore to find that clinical application of the knowledge accrued over this period of time has lagged behind. In part at least this may reflect the controversy concerning whether CD200 represents the optimal ligands for all CD200Rs, and the pleiotropic, and possibly unpredictable, effects initiated if broad stimulation of CD200Rs is induced. Sufficient evidence is now coming to light, however, to suggest that more defined agonist (and antagonist) ligands of different CD200Rs can be characterized and that unique anti-CD200Rs themselves (as well as anti-CD200) may possess greater specificity (of immunoregulation) than CD200 itself. If this promise is upheld, we can anticipate the next decade may yield even more interesting information concerning the therapeutic effects of interrupting CD200:CD200R interactions in human disease.

\section{Acknowledgments}

The work in the author's laboratory has been supported by research grants from the Canadian Institutes for Health Research (CIHR); Canadian Space Agency; Heart and Stroke Foundation; Cancer Research Society; National Cancer Institute of Canada (NCIC). Drs. Karrie Wong and Ismat Khatri contributed helpful advice in the preparation of this paper.

\section{References}

[1] A. N. Barclay and H. A. Ward, "Purification and chemical characterisation of membrane glycoproteins from rat thymocytes and brain, recognised by monoclonal antibody MRC 
OX2," European Journal of Biochemistry, vol. 129, no. 2, pp. 447-458, 1982.

[2] W. R. McMaster and A. F. Williams, "Monoclonal antibodies to Ia antigens from rat thymus: cross reactions with mouse and human and use in purification of rat Ia glycoproteins," Immunological Reviews, vol. 47, pp. 117-137, 1979.

[3] A. D. Dick, C. Broderick, J. V. Forrester, and G. J. Wright, "Distribution of OX2 antigen and OX2 receptor within retina," Investigative Ophthalmology and Visual Science, vol. 42, no. 1, pp. 170-176, 2001.

[4] M. D. Rosenblum, E. B. Olasz, K. B. Yancey et al., "Expression of CD200 on epithelial cells of the murine hair follicle: a role in tissue-specific immune tolerance?" Journal of Investigative Dermatology, vol. 123, no. 5, pp. 880-887, 2004.

[5] D. A. Clark, A. Keil, Z. Chen, U. Markert, J. Manuel, and R. M. Gorczynski, "Placental trophoblast from successful human pregnancies expresses the tolerance signaling molecule, CD200 (OX-2)," American Journal of Reproductive Immunology, vol. 50, no. 3, pp. 187-195, 2003.

[6] G. J. Wright, H. Cherwinski, M. Foster-Cuevas et al., "Characterization of the CD200 receptor family in mice and humans and their interactions with CD200," The Journal of Immunology, vol. 171, no. 6, pp. 3034-3046, 2003.

[7] R. Gorczynski, Z. Q. Chen, Y. Kai, L. Lee, S. Wong, and P. A. Marsden, "CD200 is a ligand for all members of the CD200R family of immunoregulatory molecules," The Journal of Immunology, vol. 172, no. 12, pp. 7744-7749, 2004.

[8] D. Hatherley, H. M. Cherwinski, M. Moshref, and A. N. Barclay, "Recombinant CD200 protein does not bind activating proteins closely related to CD200 receptor," The Journal of Immunology, vol. 175, no. 4, pp. 2469-2474, 2005.

[9] A. E. Morelli and A. W. Thomson, "Tolerogenic dendritic cells and the quest for transplant tolerance," Nature Reviews Immunology, vol. 7, no. 8, pp. 610-621, 2007.

[10] S. Gordon, "Alternative activation of macrophages," Nature Reviews Immunology, vol. 3, pp. 23-35, 2003.

[11] Z. S. Nagy, J. Ross, H. Cheng, S. M. Stepkowski, and R. A. Kirken, "Regulation of lymphoid cell apoptosis by Jaks and Stats," Critical Reviews in Immunology, vol. 24, no. 2, pp. 87110, 2004.

[12] J. V. Ravetch and L. L. Lanier, "Immune inhibitory receptors," Science, vol. 290, no. 5489, pp. 84-89, 2000.

[13] P. R. Taylor, L. Martinez-Pomares, M. Stacey, H. H. Lin, G. D. Brown, and S. Gordon, "Macrophage receptors and immune recognition," Annual Review of Immunology, vol. 23, pp. 901944, 2005.

[14] M. Lucas, L. Daniel, E. Tomasello et al., "Massive inflammatory syndrome and lymphocytic immunodeficiency in KARAP/DAP12-transgenic mice," European Journal of Immunology, vol. 32, no. 9, pp. 2653-2663, 2002.

[15] P. A. Oldenborg, "Role of CD47 in erythroid cells and in autoimmunity," Leukemia and Lymphoma, vol. 45, no. 7, pp. 1319-1327, 2004.

[16] M. Colonna, "TREMs in the immune system and beyond," Nature Reviews Immunology, vol. 3, no. 6, pp. 445-453, 2003.

[17] G. J. Wright, M. J. Puklavec, A. C. Willis et al., "Lymphoid/neuronal cell surface OX2 glycoprotein recognizes a novel receptor on macrophages implicated in the control of their function," Immunity, vol. 13, no. 2, pp. 233-242, 2000.

[18] A. Kharitonenkov, Z. Chen, I. Sures, H. Wang, J. Schilling, and A. Ullrich, "A family of proteins that inhibit signalling through tyrosine kinase receptors," Nature, vol. 386, no. 6621, pp. 181-186, 1997.
[19] F. Borriello, J. Lederer, S. Scott, and A. H. Sharpe, "MRC OX2 defines a novel T cell costimulatory pathway," The Journal of Immunology, vol. 158, no. 10, pp. 4548-4554, 1997.

[20] R. M. Gorczynski, M. S. Cattral, Z. G. Chen et al., "An immunoadhesin incorporating the molecule OX-2 is a potent immunosuppressant that prolongs allo- and xenograft survival," The Journal of Immunology, vol. 163, no. 3, pp. 1654-1660, 1999.

[21] R. M. Gorczynski, Z. Chen, Y. Kai, and J. Lei, "Evidence for persistent expression of OX2 as a necessary component of prolonged renal allograft survival following portal vein immunization," Clinical Immunology, vol. 97, no. 1, pp. 69$78,2000$.

[22] D. Hatherley and A. N. Barclay, "The CD200 and CD200 receptor cell surface proteins interact through their $\mathrm{N}$ terminal immunoglobulin-like domains," European Journal of Immunology, vol. 34, no. 6, pp. 1688-1694, 2004.

[23] P. A. van der Merwe and A. N. Barclay, "Analysis of cell-adhesion molecule interactions using surface plasmon resonance," Current Opinion in Immunology, vol. 8, no. 2, pp. 257-261, 1996.

[24] R. Gorczynski, I. Boudakov, and I. Khatri, "Peptides of CD200 modulate LPS-Induced TNF-alpha induction and mortality in vivo," Journal of Surgical Research, vol. 145, no. 1, pp. 87-96, 2008.

[25] R. M. Gorczynski, I. Boudakov, and I. Khatri, "A comparison of the biological properties of small molecular weight agonists and antagonists of CD200:CD200R interactions," Medicinal Chemistry, vol. 4, no. 6, pp. 624-631, 2008.

[26] J. A. Hamerman, N. K. Tchao, C. A. Lowell, and L. L. Lanier, "Enhanced Toll-like receptor responses in the absence of signaling adaptor DAP12," Nature Immunology, vol. 6, no. 6, pp. 579-586, 2005.

[27] H. Kubagawa, C. C. Chen, L. H. Ho et al., "Biochemical nature and cellular distribution of the paired immunoglobulin-like receptors, PIR-A and PIR-B," Journal of Experimental Medicine, vol. 189, no. 2, pp. 309-317, 1999.

[28] J. Samaridis and M. Colonna, "Cloning of novel immunoglobulin superfamily receptors expressed on human myeloid and lymphoid cells: structural evidence for new stimulatory and inhibitory pathways," European Journal of Immunology, vol. 27, no. 3, pp. 660-665, 1997.

[29] J. Dietrich, M. Cella, M. Seiffert, H. J. Bühring, and M. Colonna, "Cutting edge: signal-regulatory protein $\beta 1$ is a DAP12-associated activating receptor expressed in myeloid cells," The Journal of Immunology, vol. 164, no. 1, pp. 9-12, 2000.

[30] S. Zhang and J. H. Phillips, "Identification of tyrosine residues crucial for CD200R-mediated inhibition of mast cell activation," Journal of Leukocyte Biology, vol. 79, no. 2, pp. 363-368, 2006.

[31] S. L. Zhang, H. Cherwinski, J. D. Sedgwick, and J. H. Phillips, "Molecular mechanisms of CD200 inhibition of mast cell activation," The Journal of Immunology, vol. 173, no. 11, pp. 6786-6793, 2004.

[32] R. Mihrshahi and M. H. Brown, "Downstream of tyrosine kinase 1 and 2 play opposing roles in CD200 receptor signaling," The Journal of Immunology, vol. 185, no. 12, pp. 7216-7222, 2010.

[33] R. M. Gorczynski, "Transplant tolerance modifying antibody, to CD200 receptor, but not CD200, alters cytokine production profile from stimulated macrophages," European Journal of Immunology, vol. 31, no. 8, pp. 2331-2337, 2001. 
[34] I. Boudakov, P. Chang, and R. M. Gorczynski, "Mechanisms involved in suppression induced by CD200:CD200R interaction," Recent Research Developments in Immunology, vol. 7, pp. 9-24, 2005.

[35] R. M. Gorczynski, I. Khatri, L. Lee, and I. Boudakov, "An interaction between CD200 and monoclonal antibody agonists to CD200R2 in development of dendritic cells that preferentially induce populations of $\mathrm{CD} 4^{+} \mathrm{CD} 25^{+} \mathrm{T}$ regulatory cells," The Journal of Immunology, vol. 180, no. 9, pp. 5946-5955, 2008.

[36] D. Voehringer, D. B. Rosen, L. L. Lanier, and R. M. Locksley, "CD200 receptor family members represent novel DAP12associated activating receptors on basophils and mast cells," The Journal of Biological Chemistry, vol. 279, no. 52, pp. 54117-54123, 2004.

[37] I. Khatri, I. Boudakov, B. Lamptey et al., "Structural and functional consequences of switching carboxy terminal domains in mouse CD200 receptors," Open Journal of Immunology. In press.

[38] A. L. Mellor and D. H. Munn, "IDO expression by dendritic cells: tolerance and tryptophan catabolism," Nature Reviews Immunology, vol. 4, no. 10, pp. 762-774, 2004.

[39] F. Fallarino, C. Asselin-Paturel, C. Vacca et al., "Murine plasmacytoid dendritic cells initiate the immunosuppressive pathway of tryptophan catabolism in response to CD200 receptor engagement," The Journal of Immunology, vol. 173, no. 6, pp. 3748-3754, 2004.

[40] M. C. Jenmalm, H. Cherwinski, E. P. Bowman, J. H. Phillips, and J. D. Sedgwick, "Regulation of myeloid cell function through the CD200 receptor," The Journal of Immunology, vol. 176, no. 1, pp. 191-199, 2006.

[41] E. S. K. Rijkers, T. de Ruiter, A. Baridi, H. Veninga, R. M. Hoek, and L. Meyaard, "The inhibitory CD200R is differentially expressed on human and mouse $\mathrm{T}$ and $\mathrm{B}$ lymphocytes," Molecular Immunology, vol. 45, no. 4, pp. 1126-1135, 2008.

[42] L. Gorczynski, Z. Chen, J. Hu et al., "Evidence that an OX-2-positive cell can inhibit the stimulation of type 1 cytokine production by bone marrow-derived B7-1 (and B72)-positive dendritic cells," The Journal of Immunology, vol. 162, no. 2, pp. 774-781, 1999.

[43] K. Sato, K. Eizumi, T. Fukaya et al., "Naturally occurring regulatory dendritic cells regulate murine cutaneous chronic graft-versus-host disease," Blood, vol. 113, no. 19, pp. 47804789, 2009.

[44] M. D. Rosenblum, E. Olasz, J. E. Woodliff et al., "CD200 is a novel p53-target gene involved in apoptosis-associated immune tolerance," Blood, vol. 103, no. 7, pp. 2691-2698, 2004.

[45] R. H. Hoek, S. R. Ruuls, C. A. Murphy et al., "Downregulation of the macrophage lineage through interaction with OX2 (CD200)," Science, vol. 290, no. 5497, pp. 1768$1771,2000$.

[46] M. B. Graeber, F. López-Redondo, E. Ikoma et al., "The microglia/macrophage response in the neonatal rat facial nucleus following axotomy," Brain Research, vol. 813, no. 2, pp. 241-253, 1998.

[47] I. K. Campbell, J. A. Hamilton, and I. P. Wicks, "Collageninduced arthritis in $\mathrm{C} 57 \mathrm{BL} / 6\left(\mathrm{H}-2^{\mathrm{b}}\right)$ mice: new insights into an important disease model of rheumatoid arthritis," European Journal of Immunology, vol. 30, no. 6, pp. 15681575, 2000.

[48] M. Robertson, L. P. Erwig, J. Liversidge, J. V. Forrester, A. J. Rees, and A. D. Dick, "Retinal micro-environment de- termines both resident and infiltrating macrophage function during experimental autoimmune uveoretinitis (EAU)," Investigative Ophthalmology \& Visual Science, vol. 44, pp. 3034-3041, 2002.

[49] C. Broderick, R. M. Hoek, J. V. Forrester, J. Liversidge, J. D. Sedgwick, and A. D. Dick, "Constitutive retinal CD200 expression regulates resident microglia and activation state of inflammatory cells during experimental autoimmune uveoretinitis," The American Journal of Pathology, vol. 161, no. 5, pp. 1669-1677, 2002.

[50] E. S. K. Rijkers, T. de Ruiter, M. Buitenhuis, H. Veninga, R. M. Hoek, and L. Meyaard, "Ligation of CD200R by CD200 is not required for normal murine myelopoiesis," European Journal of Haematology, vol. 79, no. 5, pp. 410-416, 2007.

[51] R. M. Gorczynski, Z. Chen, I. Khatri, and K. Yu, "sCD200 isoforms present in mice receiving skin allografts cause immunosuppression in vitro and induce Tregs," The Journal of Immunology. In press.

[52] R. M. Gorczynski, D. A. Clark, N. Erin, and I. Khatri, "Role of CD200 expression in regulation of metastasis of EMT6 tumor cells in mice," Breast Cancer Research and Treatment, vol. 130, no. 1, pp. 49-60, 2010.

[53] W. G. Cui, E. Cuartas, J. Ke et al., "CD200 and its receptor, CD200R, modulate bone mass via the differentiation of osteoclasts," Proceedings of the National Academy of Sciences of the United States of America, vol. 104, no. 36, pp. 1443614441, 2007.

[54] L. Lee, O. Kos, and R. M. Gorczynski, "Altered expression of mRNAs implicated in osteogenesis under conditions of simulated microgravity is regulated by CD200:CD200R," Acta Astronautica, vol. 63, no. 11-12, pp. 1326-1336, 2008.

[55] L. Lee, J. Liu, J. Manuel, and R. M. Gorczynski, "A role for the immunomodulatory molecules CD200 and CD200R in regulating bone formation," Immunology Letters, vol. 105, no. 2, pp. 150-158, 2006.

[56] O. Kos, L. Lee, and R. M. Gorczynski, “CD200:CD200R interactions regulate osteoblastogenesis and osteoclastogenesis in space," Journal of Gravitational Physiology, vol. 15, no. 1, pp. 109-111, 2008.

[57] R. J. Snelgrove, J. Goulding, A. M. Didierlaurent et al., "A critical function for CD200 in lung immune homeostasis and the severity of influenza infection," Nature Immunology, vol. 9, no. 9, pp. 1074-1083, 2008.

[58] E. S. K. Rijkers, T. P. Rygiel, T. de Ruiter et al., "CD200 controls pathological T cell responses duringinfluenza infection," PLoS One, vol. 7, 2012.

[59] K. Yu, Z. Q. Chen, S. N. Wang, and R. Gorczynski, "Decreased alloreactivity using donor cells from mice expressing a CD200 transgene under control of a tetracycline-inducible promoter," Transplantation, vol. 80, no. 3, pp. 394-401, 2005.

[60] R. M. Gorczynski, Z. Q. Chen, W. He et al., "Expression of a CD200 transgene is necessary for induction but not maintenance of tolerance to cardiac and skin allografts," The Journal of Immunology, vol. 183, no. 3, pp. 1560-1568, 2009.

[61] R. M. Gorczynski, Z. Q. Chen, J. Diao et al., "Breast cancer cell CD200 expression regulates immune response to EMT6 tumor cells in mice," Breast Cancer Research and Treatment, vol. 123, no. 2, pp. 405-415, 2010.

[62] K. Yu and R. Gorczynski, "Persistence of gene expression profile in CD200 transgenic skin allografts is associated with graft survival on retransplantation to normal recipients," Transplantation, vol. 94, no. 1, pp. 36-42, 2012.

[63] I. Boudakov, J. Liu, N. Fan, P. Gulay, K. Wong, and R. M. Gorczynski, "Mice lacking CD200R1 show absence of 
suppression of lipopolysaccharide-induced tumor necrosis factor- $\alpha$ and mixed leukocyte culture responses by CD200," Transplantation, vol. 84, no. 2, pp. 251-257, 2007.

[64] R. M. Gorczynski, "CD200 and its receptors as targets for immunoregulation," Current Opinion in Investigational Drugs, vol. 6, no. 5, pp. 483-488, 2005.

[65] R. M. Gorczynski, L. Lee, and I. Boudakov, "Augmented induction of $\mathrm{CD}^{+} \mathrm{CD} 25^{+}$treg using monoclonal antibodies to CD200R," Transplantation, vol. 79, no. 4, pp. 488-491, 2005.

[66] K. Yu, Z. Chen, and R. M. Gorczynski, "Effect of CD200 and CD200R1 expression within tissue grafts on increased graft survival in allogeneic recipients," Immunology Letters. In press.

[67] R. D. Stout and J. Suttles, "Functional plasticity of macrophages: reversible adaptation to changing microenvironments," Journal of Leukocyte Biology, vol. 76, no. 3, pp. 509-513, 2004.

[68] R. D. Stout, S. K. Watkins, and J. Suttles, "Functional plasticity of macrophages: in situ reprogramming of tumorassociated macrophages," Journal of Leukocyte Biology, vol. 86, no. 5, pp. 1105-1109, 2009.

[69] Y. C. Ko, H. F. Chien, Y. F. Jiang-Shieh et al., "Endothelial CD200 is heterogeneously distributed, regulated and involved in immune cell-endothelium interactions," Journal of Anatomy, vol. 214, no. 1, pp. 183-195, 2009.

[70] Z. Chen, P. A. Marsden, and R. M. Gorczynski, "Cloning and characterization of the human CD200 promoter region," Molecular Immunology, vol. 43, no. 6, pp. 579-587, 2006.

[71] Z. Q. Chen, P. A. Marsden, and R. M. Gorczynski, "Role of a distal enhancer in the transcriptional responsiveness of the human CD200 gene to interferon- $\gamma$ and tumor necrosis factor- $\alpha$," Molecular Immunology, vol. 46, no. 10, pp. 19511963, 2009.

[72] A. N. Barclay, "Membrane proteins with immunoglobulinlike domains-a master superfamily of interaction molecules," Seminars in Immunology, vol. 15, no. 4, pp. 215-223, 2003.

[73] M. Foster-Cuevas, G. J. Wright, M. J. Puklavec, M. H. Brown, and A. N. Barclay, "Human herpesvirus 8 K14 protein mimics CD200 in down-regulating macrophage activation through CD200 receptor," Journal of Virology, vol. 78, no. 14, pp. 7667-7676, 2004.

[74] M. Foster-Cuevas, T. Westerholt, M. Ahmed, M. H. Brown, A. N. Barclay, and S. Voigt, "Cytomegalovirus e127 protein interacts with the inhibitory CD200 receptor," Journal of Virology, vol. 85, no. 12, pp. 6055-6059, 2011.

[75] C. M. Cameron, J. W. Barrett, L. Y. Liu, A. R. Lucas, and G. McFadden, "Myxoma virus M141R expresses a viral CD200 (vOX-2) that is responsible for down-regulation of macrophage and T-cell activation in vivo," Journal of Virology, vol. 79, no. 10, pp. 6052-6067, 2005.

[76] H. Arase, E. S. Mocarski, A. E. Campbell, A. B. Hill, and L. L. Lanier, "Direct recognition of cytomegalovirus by activating and inhibitory NK cell receptors," Science, vol. 296, no. 5571, pp. 1323-1326, 2002.

[77] S. J. Galli, J. Kalesnikoff, M. A. Grimbaldeston, A. M. Piliponsky, C. M. M. Williams, and M. Tsai, "Mast cells as "tunable" effector and immunoregulatory cells: recent advances," Annual Review of Immunology, vol. 23, pp. 749786, 2005.

[78] H. M. Cherwinski, C. A. Murphy, B. L. Joyce et al., "The $\mathrm{CD} 200$ receptor is a novel and potent regulator of murine and human mast cell function," The Journal of Immunology, vol. 174, no. 3, pp. 1348-1356, 2005.

[79] R. M. Gorczynski, Z. Chen, H. Zeng, L. Gorczynski, and E. Terzioglu, "Analysis of cytokine production and V $\beta$ Tcell receptor subsets in irradiated recipients receiving portal or peripheral venous reconstitution with allogeneic bone marrow cells, with or without additional anti-cytokine monoclonal antibodies," Immunology, vol. 93, no. 2, pp. 221229, 1998.

[80] R. M. Gorczynski, J. Hu, Z. Chen, Y. Kai, and J. Lei, "A CD200Fc immunoadhesin prolongs rat islet xenograft survival in mice," Transplantation, vol. 73, no. 12, pp. 19481953, 2002.

[81] R. M. Gorczynski, K. Yu, and D. Clark, "Receptor engagement on cells expressing a ligand for the tolerance-inducing molecule OX2 induces an immunoregulatory population that inhibits alloreactivity in vitro and in vivo," The Journal of Immunology, vol. 165, no. 9, pp. 4854-4860, 2000.

[82] R. M. Gorczynski, Z. Q. Chen, Y. Kai, S. Wong, and L. Lee, "Induction of tolerance-inducing antigen-presenting cells in bone marrow cultures in vitro using monoclonal antibodies to CD200R," Transplantation, vol. 77, no. 8, pp. 1138-1144, 2004.

[83] K. Yu, Z. Chen, S. Wang, and R. M. Gorczynski, "Decreased alloreactivity using donor cells from mice expressing a CD200 transgene under control of a tetracycline-inducible promoter," Transplantation, vol. 80, no. 3, pp. 394-401, 2005.

[84] R. M. Gorczynski, Z. Chen, I. Khatri, and K. Yu, "Graftinfiltrating cells expressing a CD200 transgene prolong allogeneic skin graft survival in association with local increases in Foxp $3^{+}$Treg and mast cells," Transplant Immunology, vol. 25, no. 4, pp. 187-193, 2011.

[85] K. Yu, Z. Chen, I. Khatri, and R. M. Gorczynski, "CCR4 dependent migration of Foxp $3^{+} \mathrm{T}_{\text {reg }}$ cells to skin grafts and draining lymph nodes is implicated in enhanced graft survival in CD200tg recipients," Immunology Letters, vol. 141, no. 1, pp. 116-122, 2011.

[86] D. J. Chung, M. Rossi, E. Romano et al., "Indoleamine 2,3dioxygenase-expressing mature human monocyte-derived dendritic cells expand potent autologous regulatory T cells," Blood, vol. 114, no. 3, pp. 555-563, 2009.

[87] M. D. Sharma, D. Y. Hou, Y. Liu et al., "Indoleamine 2,3dioxygenase controls conversion of Foxp $3^{+}$Tregs to TH17like cells in tumor-draining lymph nodes," Blood, vol. 113, no. 24, pp. 6102-6111, 2009.

[88] T. Onodera, M. H. Jang, Z. J. Guo et al., "Constitutive expression of IDO by dendritic cells of mesenteric lymph nodes: functional involvement of the CTLA-4/B7 and CCL22/CCR4 interactions," The Journal of Immunology, vol. 183, no. 9, pp. 5608-5614, 2009.

[89] S. Piconese, G. Gri, C. Tripodo et al., "Mast cells counteract regulatory T-cell suppression through interleukin-6 and OX40/OX40L axis toward Th17-cell differentiation," Blood, vol. 114, no. 13, pp. 2639-2648, 2009.

[90] M. Veldhoen, R. J. Hocking, C. J. Atkins, R. M. Locksley, and B. Stockinger, "TGF $\beta$ in the context of an inflammatory cytokine milieu supports de novo differentiation of IL-17producing T cells," Immunity, vol. 24, no. 2, pp. 179-189, 2006.

[91] M. Boerma, W. P. Fiser, G. Hoyt et al., "Influence of mast cells on outcome after heterotopic cardiac transplantation in rats," Transplant International, vol. 20, no. 3, pp. 256-265, 2007. 
[92] V. C. de Vries, A. Wasiuk, K. A. Bennett et al., "Mast cell degranulation breaks peripheral tolerance," American Journal of Transplantation, vol. 9, no. 10, pp. 2270-2280, 2009.

[93] M. Veldhoen, C. Uyttenhove, J. van Snick et al., "Transforming growth factor- $\beta$ 'reprograms' the differentiation of $\mathrm{T}$ helper 2 cells and promotes an interleukin 9-producing subset," Nature Immunology, vol. 9, no. 12, pp. 1341-1346, 2008.

[94] W. Zhang, K. Wu, W. He et al., "Transforming growth factor beta 1 plays an important role in inducing $\mathrm{CD} 4{ }^{+} \mathrm{CD} 25^{+}$forhead box $\mathrm{P}^{+}$regulatory $\mathrm{T}$ cells by mast cells," Clinical and Experimental Immunology, vol. 161, no. 3, pp. 490-496, 2010.

[95] K. Eller, D. Wolf, J. M. Huber et al., "IL-9 production by regulatory $\mathrm{T}$ cells recruits mast cells that are essential for regulatory T cell-induced immune suppression," The Journal of Immunology, vol. 186, no. 1, pp. 83-91, 2011.

[96] W. Elyaman, E. M. Bradshaw, C. Uyttenhove et al., "IL-9 induces differentiation of TH17 cells and enhances function of $\mathrm{FoxP}^{+}$natural regulatory $\mathrm{T}$ cells," Proceedings of the National Academy of Sciences of the United States of America, vol. 106, no. 31, pp. 12885-12890, 2009.

[97] C. A. Da Silva, M. Adda, M. Stern, F. de Blay, N. Frossard, and D. Israel-Biet, "Marked stem cell factor expression in the airways of lung transplant recipients," Respiratory Research, vol. 7, article 90, 2006.

[98] M. Stassen, M. Arnold, L. Hültner et al., "Murine bone marrow-derived mast cells as potent producers of IL-9: costimulatory function of IL-10 and kit ligand in the presence of IL-1," The Journal of Immunology, vol. 164, no. 11, pp. 5549-5555, 2000.

[99] R. Sembeil, K. Sanhadji, G. Vivier, J. Chargui, and J. L. Touraine, "Prolonged survival of mouse skin allografts after transplantation of fetal liver cells transduced with hIL-10 gene," Transplant Immunology, vol. 13, no. 1, pp. 1-8, 2004.

[100] Z. Chen, D.-X. Chen, Y. Kai, I. Khatri, B. Lamptey, and R. M. Gorczynski, "Identification of an expressed truncated form of CD200, CD200tr, which is a physiologic antagonist of CD200-induced suppression," Transplantation, vol. 86, no. 8, pp. 1116-1124, 2008.

[101] D. Miyazaki, T. Nakamura, M. Toda, K. W. Cheung-Chau, R. M. Richardson, and S. J. Ono, "Macrophage inflammatory protein- $1 \alpha$ as a costimulatory signal for mast cell-mediated immediate hypersensitivity reactions," The Journal of Clinical Investigation, vol. 115, no. 2, pp. 434-442, 2005.

[102] V. C. de Vries and R. J. Noelle, "Mast cell mediators in tolerance," Current Opinion in Immunology, vol. 22, no. 5, pp. 643-648, 2010.

[103] C. P. Blobel, "ADAMs: key components in EGFR signalling and development," Nature Reviews Molecular Cell Biology, vol. 6, no. 1, pp. 32-43, 2005.

[104] M. J. Duffy, E. McKiernan, N. O'Donovan, and P. M. McGowan, "The role of ADAMs in disease pathophysiology," Clinica Chimica Acta, vol. 403, no. 1-2, pp. 31-36, 2009.

[105] X. Li, Z. R. Zhang, H. J. Schluesener, and S. Q. Xu, "Role of exosomes in immune regulation," Journal of Cellular and Molecular Medicine, vol. 10, no. 2, pp. 364-375, 2006.

[106] R. Simpson and S. Mathivanan, "Extracellular microvesicles: the need for internationally recognised nomenclature and stringent purification criteria," Journal of Proteomics \& Bioinformatics, vol. 2, pp. 1-9, 2012.

[107] P. P. Singh, V. L. Smith, P. C. Karakousis, and J. S. Schorey, "Exosomes isolated from mycobacteria-infected mice or cultured macrophages can recruit and activate immune cells in vitro and in vivo," The Journal of Immunology, vol. 189, no. 2, pp. 777-785, 2012.

[108] H. Peinado, M. Aleckovic, S. Lavotshkin et al., "Melanoma exosomes educate bone marrow progenitor cells towar a prometastatic phenotype through MET," Nature Medicine, vol. 18, pp. 883-891, 2012.

[109] C. Yang, M. A. Ruffner, S.-H. Kim, and P. D. Robbins, "Plasma-derived MHC class $\mathrm{II}^{+}$exosomes from tumorbearing mice suppress tumor antigen-specific immune responses," European Journal of Immunology, vol. 42, no. 7, pp. 1778-1784, 2012.

[110] R. M. Gorczynski, S. Hadidi, G. Yu, and D. A. Clark, "The same immunoregulatory molecules contribute to successful pregnancy and transplantation," American Journal of Reproductive Immunology, vol. 48, no. 1, pp. 18-26, 2002.

[111] D. A. Clark and G. Chaouat, "Loss of surface CD200 on stored allogeneic leukocytes may impair anti-abortive effect in vivo," American Journal of Reproductive Immunology, vol. 53, no. 1, pp. 13-20, 2005.

[112] D. A. Clark, K. Wong, D. Banwatt et al., "CD200-dependent and nonCD200-dependant pathways of NK cell suppression by human IVIG," Journal of Assisted Reproduction and Genetics, vol. 25, no. 2-3, pp. 67-72, 2008.

[113] G. Yu, Y. Sun, K. Foerster et al., "LPS-induced murine abortions require $\mathrm{C} 5$ but not $\mathrm{C} 3$, and are prevented by upregulating expression of the CD200 tolerance signaling molecule," American Journal of Reproductive Immunology, vol. 60, no. 2, pp. 135-140, 2008.

[114] D. A. Clark, J. Manuel, L. Lee, G. Chaouat, R. M. Gorczynski, and G. A. Levy, "Ecology of danger-dependent cytokineboosted spontaneous abortion in the CBA $\times$ DBA $/ 2$ mouse model. I. Synergistic effect of LPS (TNF- $\alpha+$ IFN- $\gamma$ ) on pregnancy loss," American Journal of Reproductive Immunology, vol. 52, no. 6, pp. 370-378, 2004.

[115] D. X. Chen, H. He, and R. M. Gorczynski, "Synthetic peptides from the N-terminal regions of CD200 and CD200R1 modulate immunosuppressive and anti-inflammatory effects of CD200-CD200R1 interaction," International Immunology, vol. 17, no. 3, pp. 289-296, 2005.

[116] D. X. Chen and R. M. Gorczynski, "Discrete monoclonal antibodies define functionally important epitopes in the CD200 molecule responsible for immunosuppression function," Transplantation, vol. 79, no. 3, pp. 282-288, 2005.

[117] K. Kawamoto, A. Pahuja, B. J. Hering, and P. BansalPakala, "Transforming growth factor beta 1 (TGF- $\beta 1$ ) and rapamycin synergize to effectively suppress human $\mathrm{T}$ cell responses via upregulation of $\mathrm{FoxP}^{+}$Tregs," Transplant Immunology, vol. 23, no. 1-2, pp. 28-33, 2010.

[118] R. M. Gorczynski, Z. Q. Chen, S. Shivagnahnam et al., "Potent immunosuppression by a bivalent molecule binding to CD200R and TGF- $\beta$ R," Transplantation, vol. 90, no. 2, pp. 150-159, 2010.

[119] R. M. Steinman, "Dendritic cells: understanding immunogenicity," European Journal of Immunology, vol. 37, no. 1, pp. S53-S60, 2007.

[120] J. Mahoney and A. Rosen, "Apoptosis and autoimmunity," Current Opinion in Immunology, vol. 17, no. 6, pp. 583-588, 2005.

[121] F. Fallarino, U. Grohmann, S. You et al., "Tryptophan catabolism generates autoimmune-preventive regulatory T cells," Transplant Immunology, vol. 17, no. 1, pp. 58-60, 2006.

[122] R. M. Gorczynski, Z. Q. Chen, K. Yu, and J. Hu, "CD200 immunoadhesin suppresses collagen-induced arthritis in mice," Clinical Immunology, vol. 101, no. 3, pp. 328-334, 2001. 
[123] R. M. Gorczynski, Z. Chen, L. Lee, K. Yu, and J. Hu, "AntiCD200R ameliorates collagen-induced arthritis in mice," Clinical Immunology, vol. 104, no. 3, pp. 256-264, 2002.

[124] M. C. Melnyk, I. Shalev, J. Zhang et al., "The prothrombinase activity of FGL2 contributes to the pathogenesis of experimental arthritis," Scandinavian Journal of Rheumatology, vol. 40, no. 4, pp. 269-278, 2011.

[125] E. Šimelyte, G. Criado, D. Essex, R. A. Uger, M. Feldmann, and R. O. Williams, "CD200-Fc, a novel antiarthritic biologic agent that targets proinflammatory cytokine expression in the joints of mice with collagen-induced arthritis," Arthritis and Rheumatism, vol. 58, no. 4, pp. 1038-1043, 2008.

[126] M. D. Rosenblum, K. B. Yancey, E. B. Olasz, and R. L. Truitt, "CD200, a "no danger" signal for hair follicles," Journal of Dermatological Science, vol. 41, no. 3, pp. 165-174, 2006.

[127] N. Taylor, K. McConnachie, C. Calder et al., "Enhanced tolerance to autoimmune uveitis in CD200-deficient mice correlates with a pronounced Th2 switch in response to antigen challenge," The Journal of Immunology, vol. 174, no. 1, pp. 143-154, 2005.

[128] A. D. Dick, Y. F. Cheng, J. Liversidge, and J. V. Forrester, "Immunomodulation of experimental autoimmune uveoretinitis: a model, of tolerance induction with retinal antigens," Eye, vol. 8, part 1, pp. 52-59, 1994.

[129] D. A. Copland, C. J. Calder, B. J. E. Raveney et al., "Monoclonal antibody-mediated CD200 receptor signaling suppresses macrophage activation and tissue damage in experimental autoimmune uveoretinitis," The American Journal of Pathology, vol. 171, no. 2, pp. 580-588, 2007.

[130] A. D. Dick, D. Carter, M. Robertson et al., "Control of myeloid activity during retinal inflammation," Journal of Leukocyte Biology, vol. 74, no. 2, pp. 161-166, 2003.

[131] Y. Li, L. D. Zhao, L. S. Tong et al., "Aberrant CD200/CD200R1 expression and function in systemic lupus erythematosus contributes to abnormal T-cell responsiveness and dendritic cell activity," Arthritis Research \& Therapy, vol. 14, article R123, 2012.

[132] D. Banerjee and A. D. Dick, "Blocking CD200-CD200 receptor axis augments NOS-2 expression and aggravates experimental autoimmune uveoretinitis in Lewis rats," Ocular Immunology and Inflammation, vol. 12, no. 2, pp. 115125, 2004.

[133] T. Chitnis, J. Imitola, Y. Wang et al., "Elevated neuronal expression of CD200 protects Wlds mice from inflammationmediated neurodegeneration," The American Journal of Pathology, vol. 170, no. 5, pp. 1695-1712, 2007.

[134] M. G. Frank, M. V. Baratta, D. B. Sprunger, L. R. Watkins, and S. F. Maier, "Microglia serve as a neuroimmune substrate for stress-induced potentiation of CNS pro-inflammatory cytokine responses," Brain, Behavior, and Immunity, vol. 21, no. 1, pp. 47-59, 2007.

[135] H. Matsumoto, Y. Kumon, H. Watanabe et al., "Expression of CD200 by macrophage-like cells in ischemic core of rat brain after transient middle cerebral artery occlusion," Neuroscience Letters, vol. 418, no. 1, pp. 44-48, 2007.

[136] D. G. Walker, J. E. Dalsing-Hernandez, N. A. Campbell, and L.-F. Lue, "Decreased expression of CD200 and CD200 receptor in Alzheimer's disease: a potential mechanism leading to chronic inflammation," Experimental Neurology, vol. 215, no. 1, pp. 5-19, 2009.

[137] Z. Q. Chen, X. Z. Ma, J. H. Zhang, J. Hu, and R. M. Gorczynski, "Alternative splicing of CD200 is regulated by an exonic splicing enhancer and SF2/ASF," Nucleic Acids Research, vol. 38, no. 19, pp. 6684-6696, 2010.
[138] S. Voight, G. R. Sandford, G. S. Hayward, and W. H. Burns, "The English strain of rat cytomegalovirus (CMV) contains a novel captured CD200 (vOX2) gene and a spliced CC chemokine upstream from the major immediate-early region: further evidence for a separate evolutionary lineage from that of a rat CMV Maastricht," Journal of General Virology, vol. 86, no. 2, pp. 263-274, 2005.

[139] C. L. Pratt, R. D. Estep, and S. W. Wong, "Splicing of rhesus rhadinovirus R15 and ORF74 bicistronic transcripts during lytic infection and analysis of effects on production of vCD200 and vGPCR," Journal of Virology, vol. 79, no. 6, pp. 3878-3882, 2005.

[140] S. Caserta, N. Nausch, A. Sawtell et al., "Chronic infection drives expression of the inhibitory receptor CD200R, and its ligand CD200, by mouse and human CD4 T cells," PLoS One, vol. 7, no. 4, Article ID e35466, 2012.

[141] R. M. Gorczynski, Z. Chen, J. Hu, Y. Kai, and J. Lei, "Evidence of a role for CD200 in regulation of immune rejection of leukaemic tumour cells in C57BL/6 mice," Clinical and Experimental Immunology, vol. 126, no. 2, pp. 220-229, 2001.

[142] A. Tonks, R. Hills, P. White et al., "CD200 as a prognostic factor in acute myeloid leukaemia," Leukemia, vol. 21, no. 3, pp. 566-568, 2007.

[143] J. R. McWhirter, A. Kretz-Rommel, A. Saven et al., "Antibodies selected from combinatorial libraries block a tumor antigen that plays a key role in immunomodulation," Proceedings of the National Academy of Sciences of the United States of America, vol. 103, no. 4, pp. 1041-1046, 2006.

[144] J. Moreaux, D. Hose, T. Reme et al., "CD200 is a new prognostic factor in multiple myeloma," Blood, vol. 108, pp. 4194-4197, 2006.

[145] S. J. Coles, E. C. Y. Wang, S. Man et al., "CD200 expression suppresses natural killer cell function and directly inhibits patient anti-tumor response in acute myeloid leukemia," Leukemia, vol. 25, no. 5, pp. 792-799, 2011.

[146] J. Moreaux, J. L. Veyrune, T. Reme, J. de Vos, and B. Klein, "CD200: a putative therapeutic target in cancer," Biochemical and Biophysical Research Communications, vol. 366, no. 1, pp. 117-122, 2008.

[147] R. R. Ruela-de-Sousa, K. C. Queiroz, M. P. Peppelenbosch, and G. M. Fuhler, "Reversible phosphorylation in haematological malignancies: potential role for protein tyrosine phosphatases in treatment?" Biochimica et Biophysica Acta, vol. 1806, no. 2, pp. 287-303, 2010.

[148] A. Kretz-Rommel, F. H. Qin, N. Dakappagari et al., "CD200 expression on tumor cells suppresses antitumor immunity: new approaches to cancer immunotherapy," The Journal of Immunology, vol. 178, no. 9, pp. 5595-5605, 2007.

[149] A. Kretz-Romme, F. Qin, N. Dakappagari, R. Cofiell, S. J. Faas, and K. S. Bowdish, "Blockade of CD200 in the presence or absence of antibody effector function: implications for anti-CD200 therapy," The Journal of Immunology, vol. 180, no. 2, pp. 699-705, 2008.

[150] C. P. Pallasch, S. Ulbrich, R. Brinker, M. Hallek, R. A. Uger, and C.-M. Wendtner, "Disruption of $\mathrm{T}$ cell suppression in chronic lymphocytic leukemia by CD200 blockade," Leukemia Research, vol. 33, no. 3, pp. 460-464, 2009.

[151] K. K. Wong, I. Khatri, S. Shaha, D. E. Spaner, and R. M. Gorczynski, "The role of CD200 in immunity to B cell lymphoma," Journal of Leukocyte Biology, vol. 88, no. 2, pp. 361-372, 2010.

[152] K. K. Wong, F. Brenneman, A. Chesney, D. E. Spaner, and R. M. Gorczynski, "Soluble CD200 is critical to engraft chronic 
lymphocytic leukemia cells in immunocompromised mice," Cancer Research, vol. 72, no. 19, pp. 4931-4943, 2012.

[153] A. Siva, H. Xin, F. Qin, D. Oltean, K. S. Bowdish, and A. Kretz-Rommel, "Immune modulation by melanoma and ovarian tumor cells through expression of the immunosuppressive molecule CD200," Cancer Immunology, Immunotherapy, vol. 57, no. 7, pp. 987-996, 2008.

[154] M. Stumpfova, D. Ratner, E. B. Desciak, Y. D. Eliezri, and D. M. Owens, "The immunosuppressive surface ligand CD200 augments the metastatic capacity of squamous cell carcinoma," Cancer Research, vol. 70, no. 7, pp. 2962-2972, 2010.

[155] Q. J. Huang, J. H. Yang, Y. Lin et al., "Differential regulation of interleukin 1 receptor and Toll-like receptor signaling by MEKK3,” Nature Immunology, vol. 5, no. 1, pp. 98-103, 2004.

[156] B. T. Kawasaki and W. L. Farrar, "Cancer stem cells, CD200 and immunoevasion," Trends in Immunology, vol. 29, no. 10, pp. 464-468, 2008.

[157] K. B. Petermann, G. I. Rozenberg, D. Zedek et al., "CD200 is induced by ERK and is a potential therapeutic target in melanoma," The Journal of Clinical Investigation, vol. 117, no. 12, pp. 3922-3929, 2007.

[158] K. Skalova, K. Mollova, and J. Michalek, "Human myeloid dendritic cells for cancer therapy: does maturation matter?" Vaccine, vol. 28, no. 32, pp. 5153-5160, 2010.

[159] A. Podnos, D. Clark, N. Erin, K. Yu, and R. M. Gorczynski, "Further evidence for a role of tumor CD200 expression in breast cancer metastasis: decreased metastasis in CD200R1KO mice or using CD200-silenced EMT6," Breast Cancer Research and Treatment, vol. 136, no. 1, pp. 117-127, 2012.

[160] F. Talebian, J.-Q. Liu, Z. Liu, M. Khattabi, and Y. He, "Melanoma cell expression of CD200 inhibits tumor formation and lung metastasis via inhibition of myeloid cell functions," PLoS ONE, vol. 7, no. 2, Article ID e31442, 2012.

[161] T. P. Rygiel and L. Meyaard, "CD200R signaling in tumor tolerance and inflammation: a tricky balance," Current Opinion in Immunology, vol. 24, no. 2, pp. 233-238, 2012. 


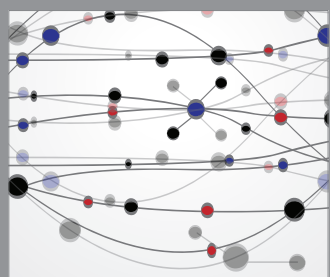

The Scientific World Journal
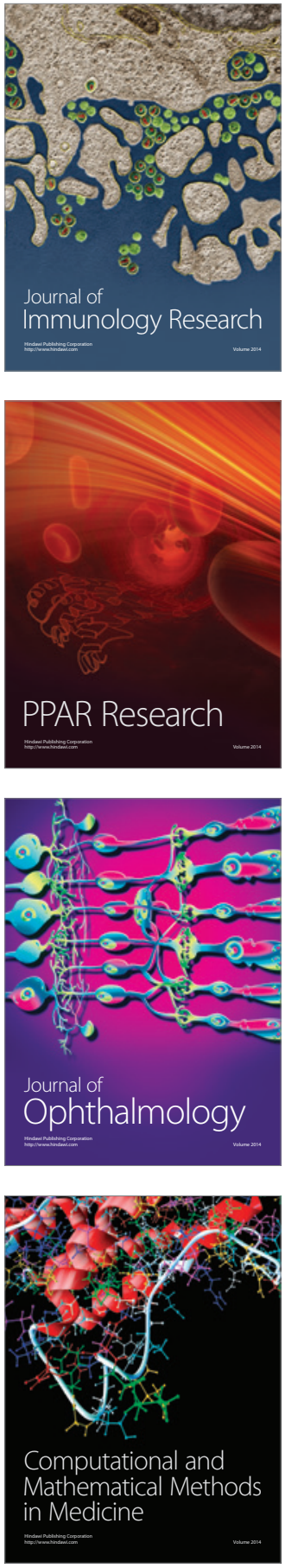

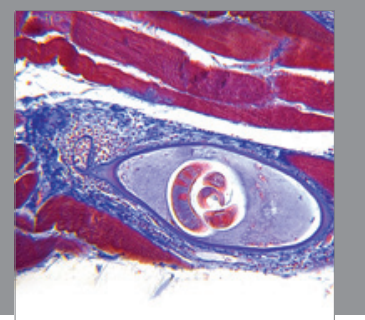

Gastroenterology

Research and Practice
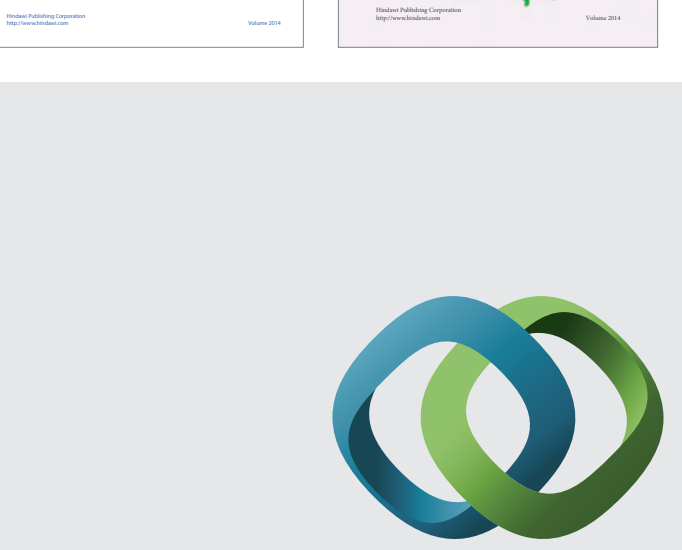

\section{Hindawi}

Submit your manuscripts at

http://www.hindawi.com
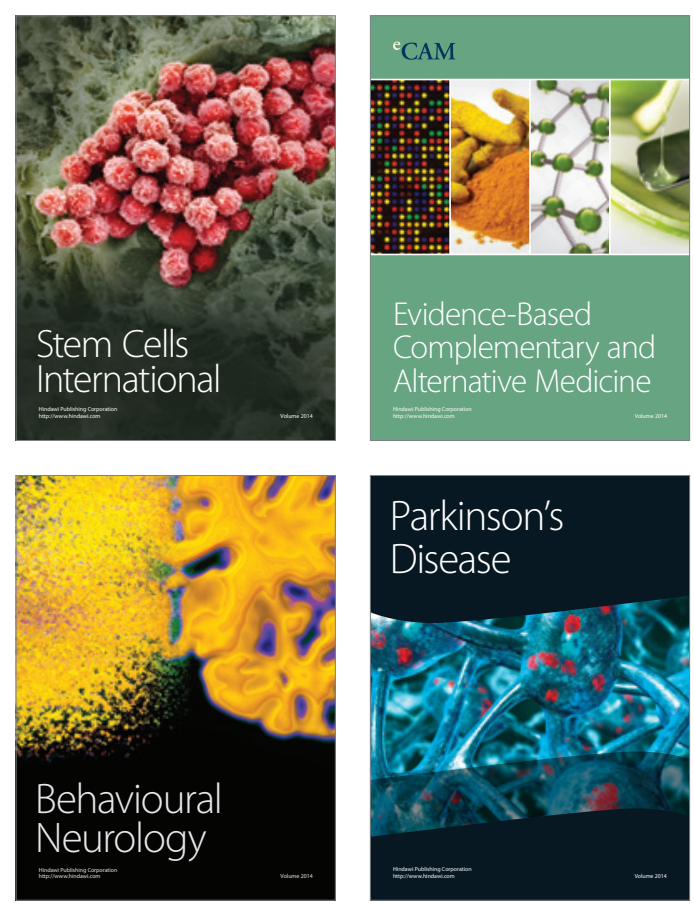

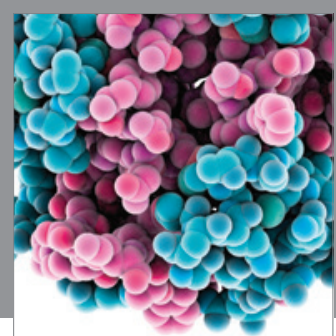

Journal of
Diabetes Research

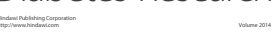

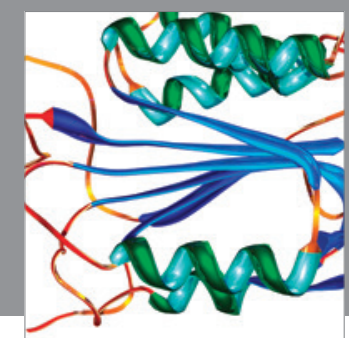

Disease Markers
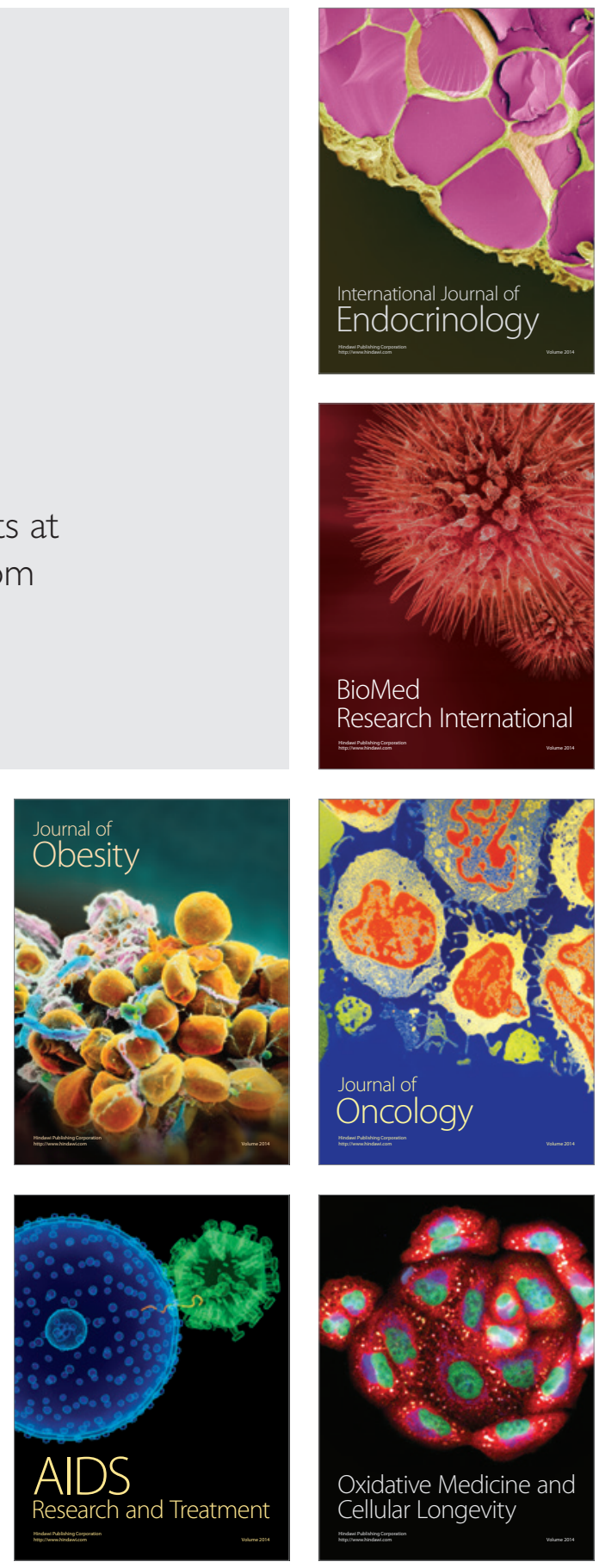